\title{
Climatology of stratocumulus cloud morphologies: microphysical properties and radiative effects
}

\author{
A. Muhlbauer ${ }^{1}$, I. L. McCoy ${ }^{2}$, and R. Wood ${ }^{3}$ \\ ${ }^{1}$ Joint Institute for the Study of the Atmosphere and Ocean, University of Washington, Seattle, Washington, USA \\ ${ }^{2}$ New Mexico Institute of Mining and Technology, Socorro, New Mexico, USA \\ ${ }^{3}$ Department of Atmospheric Sciences, University of Washington, Seattle, Washington, USA
}

Correspondence to: A. Muhlbauer (andreasm@atmos.washington.edu)

Received: 5 February 2014 - Published in Atmos. Chem. Phys. Discuss.: 14 March 2014

Revised: 12 May 2014 - Accepted: 23 May 2014 - Published: 3 July 2014

\begin{abstract}
An artificial neural network cloud classification scheme is combined with A-train observations to characterize the physical properties and radiative effects of marine low clouds based on their morphology and type of mesoscale cellular convection (MCC) on a global scale. The cloud morphological categories are (i) organized closed MCC, (ii) organized open MCC and (iii) cellular but disorganized MCC.

Global distributions of the frequency of occurrence of MCC types show clear regional signatures. Organized closed and open MCCs are most frequently found in subtropical regions and in midlatitude storm tracks of both hemispheres. Cellular but disorganized MCC are the predominant type of marine low clouds in regions with warmer sea surface temperature such as in the tropics and trade wind zones. All MCC types exhibit a pronounced seasonal cycle.

The physical properties of MCCs such as cloud fraction, radar reflectivity, drizzle rates and cloud top heights as well as the radiative effects of MCCs are found highly variable and a function of the type of MCC. On a global scale, the cloud fraction is largest for closed MCC with mean cloud fractions of about $90 \%$, whereas cloud fractions of open and cellular but disorganized MCC are only about $51 \%$ and $40 \%$, respectively. Probability density functions (PDFs) of cloud fractions are heavily skewed and exhibit modest regional variability.

PDFs of column maximum radar reflectivities and inferred cloud base drizzle rates indicate fundamental differences in the cloud and precipitation characteristics of different MCC types. Similarly, the radiative effects of MCCs differ substantially from each other in terms of shortwave reflectance and transmissivity. These differences highlight the importance of
\end{abstract}

low-cloud morphologies and their associated cloudiness on the shortwave cloud forcing.

\section{Introduction}

Marine stratocumulus (Sc) clouds are an important component of the climate system as they cover vast areas of the Earth's ocean surface and affect the radiation balance of the Earth. Owing to their high albedo, Sc reflect incoming solar radiation back to space, thereby exerting a strong negative shortwave cloud radiative effect (Hartmann and Short, 1980). Similar to other low-cloud types in the marine boundary layer (MBL), the impact of Sc clouds on the outgoing longwave radiation (OLR) is marginal due to the lack of contrast between the temperature of Sc cloud tops and the temperature of the sea surface over which they form. Thus, the net radiative effect of Sc clouds is primarily controlled by factors influencing their shortwave cloud forcing such as the cloud albedo and the cloud coverage.

Analyses of satellite imagery testify that marine Sc clouds exhibit different morphologies each resembling different types and features of embedded mesoscale cellular convection (MCC). The type of MCC is important because it modulates the overall cloud coverage and albedo of Sc cloud fields and introduces considerable mesoscale variability of the microphysical (e.g., cloud droplet number concentrations, effective radius, precipitation rate) and macrophysical (e.g., cloud albedo, cloud coverage) properties and associated radiative impacts of Sc clouds (Wood and Hartmann, 2006; Wood et al., 2011). Marine Sc may be grouped into four 
general morphological categories based on their cellularity and level of mesoscale organization. These four morphological types are (i) homogeneous overcast Sc sheets without cellularity on the mesoscale, (ii) organized closed MCC, (iii) organized open MCC and (iv) inhomogeneous disorganized cells (Wood and Hartmann, 2006; Wood, 2012).

Over subtropical eastern oceans, the types of Sc morphologies represent different stages of the Sc-topped MBL as air masses transition from shallow marine stratus forming over cold and upwelling near-coastal waters to cumulus over the warmer sea surface temperatures in trade wind regions. Homogeneous overcast marine stratus decks are dominant over near-coastal waters, whereas broken sheets of Sc with organized open or closed mesoscale cellular structure are more frequently observed further offshore. Transitions from organized open or closed mesoscale cells to larger disorganized cells of Sc and cumuli are observed further westwards as Sc clouds transit the subtropics equatorwards into the trade wind regions (Wood and Hartmann, 2006; Wood et al., 2008; Sandu et al., 2010; Wood, 2012).

Recent satellite observations suggest that approximately $65 \%$ of Sc clouds in the Southeast Pacific exhibit mesoscale cellular structures with remarkably large regional and temporal variability (Painemal et al., 2010). In many cases, observations show pockets of open cells (POCs) or cloud rifts ${ }^{1}$ forming within and surrounded by otherwise overcast sheets of Sc (e.g., Stevens et al., 2005; Sharon et al., 2006). POCs and cloud rifts are prominent examples of Sc with open MCC characteristics and contribute considerably to the cloud coverage of open cellular clouds. Observations suggest that the distribution of cloud cover contributed by Sc with open MCC is heavily skewed, with occasional contributions as large as $80 \%$ (Wood et al., 2008). Since the cloud fraction and albedo is considerably lower within POCs $(50-80 \%$ cloud fraction during VOCALS REx; Terai et al. 2014) than in the surrounding overcast Sc (approximately $100 \%$ cloud fraction), POCs, Sc cloud rifts and other marine low-cloud fields featuring open MCC are important modulators of the planetary albedo and the Earth's radiation balance. However, a systematic evaluation of the radiative impacts of MCC is still lacking.

Different types of Sc morphologies exist not only in the subtropical eastern oceans but also at mid- and high latitudes within the extratropical storm tracks and the Arctic regions. For example, sheets of Sc clouds are often found in cold sectors of midlatitude cyclones (e.g., Field and Wood, 2007) and transient Sc clouds with open or closed MCC are frequently observed in cold-air outbreaks over oceans (Atkinson and Zhang, 1996; Agee, 1987).

The major objective of this study is to conduct a global investigation of the microphysical, macrophysical and pre-

\footnotetext{
${ }^{1}$ Cloud rifts are characterized as a large-scale, persistent area of broken, low-reflectivity stratocumulus clouds usually surrounded by a solid deck of stratocumulus.
}

cipitation characteristics of different Sc cloud morphologies as well as to assess the radiative impact of Sc clouds based on their types of MCC for various regions at subtropics and midlatitudes. To achieve this goal we combine spaceborne cloud and radiation observations from active and passive remote sensors aboard the National Aeronautics and Space Administration (NASA) A-train satellite constellation with a cloud classification scheme for a full year of observations.

The paper is organized as follows: Sect. 2 introduces the cloud classification scheme and the observations used throughout this study. Section 3 discusses the climatology of Sc morphologies, including their spatial and temporal variability determined from spaceborne observations. A case study is introduced in Sect. 4 and statistics of the physical properties and radiative effects of Sc cloud morphologies are discussed in Sect. 5 and Sect. 6, respectively. Conclusions are presented in Sect. 7.

\section{Cloud classification and observations}

Our classification scheme of marine low clouds is based on previous work by Wood and Hartmann (2006) (hereafter referred to as WH06), and only some fundamental aspects of the algorithm are reviewed here to elucidate the concepts and limitations of this study. The cloud classifier is essentially a cluster analysis technique based on a three-layer back propagation artificial neural network (ANN) design, which uses power spectra and probability density functions (PDFs) of liquid water path (LWP) as a measure for distinguishing various types of marine Sc clouds by their morphology. The ANN classifier has been trained on a large set of cases identified by human observer as discussed in WH06. The Sc cloud morphology is a direct result of the type and associated features of MCC and the level of mesoscale organization within the cloud field.

The definitions of MCC types are adopted from WH06 and are (i) organized MCC with closed cellular structure, (ii) organized MCC with open cellular structure and (iii) disorganized MCC exhibiting cell-type features but lacking organization. However, in practice the latter category may also contain cloud scenes that are disorganized without clear cellular features. Example scenes of marine low clouds each representing one of the above MCC types are shown in Fig. 1. We note that the original classifier of WH06 contains a fourth MCC type, namely homogeneous Sc clouds without cellular characteristics and lacking organization. However, throughout this study we merged the homogeneous without MCC Sc cloud category with the closed MCC category because we find very little contribution to marine low-cloud fields that stem purely from the homogeneous and no-MCC category.

The input to the ANN algorithm is provided by 1 year of data from 2008 from the Moderate Resolution Imaging Spectroradiometer (MODIS), which is carried aboard the National Aeronautics and Space Administration (NASA) Aqua 

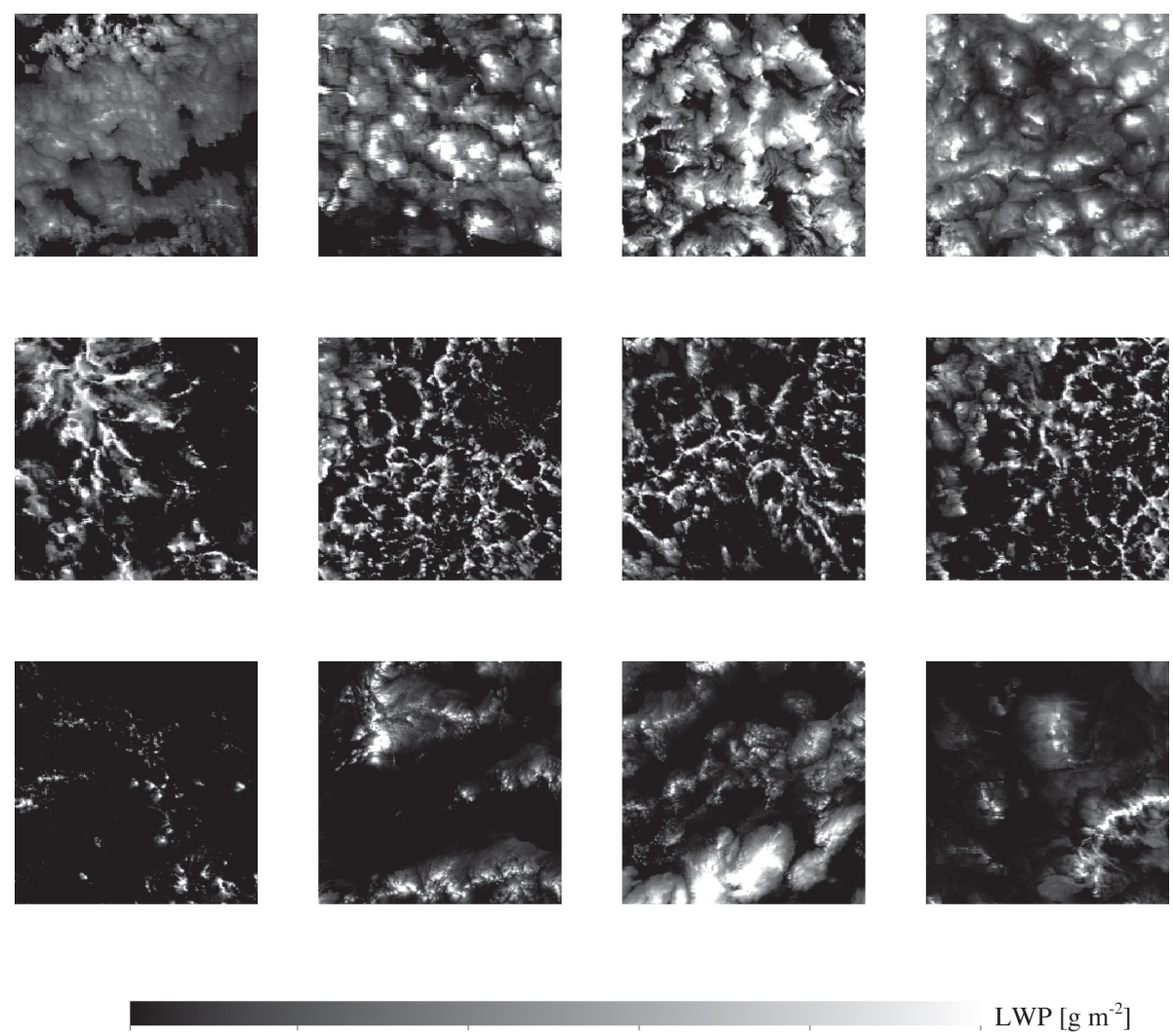

50

100

200

250

Figure 1. Example scenes of liquid water path (LWP) from MODIS Aqua for closed MCC (first row), open MCC (second row) and cellular but disorganized MCC (third row). Each scene spans an area of $256 \times 256 \mathrm{~km}^{2}$ at $1 \mathrm{~km}$ horizontal resolution.

sun-synchronous satellite. MODIS Aqua flies as part of the polar orbiting A-train satellite constellation and crosses the equator at about 13:30 local time. The MODIS collection 5 cloud product uses visible and near-infrared radiances (King et al., 1992, 2003) at $1 \mathrm{~km}$ horizontal resolution to derive optical thickness and near-cloud-top effective radius for cloudy pixels in daytime scenes. The MODIS cloud mask (Ackerman et al., 1998) is used to discriminate clear and cloudy pixels. LWP is estimated from cloud effective radius and optical thickness retrievals assuming linearly increasing cloud liquid water content (LWC) and constant cloud droplet number concentration above cloud base. The MODIS retrievals are organized as instantaneous cloud scenes and each cloud scene constitutes a $256 \times 256 \mathrm{~km}^{2}$ portion of the MODIS swath oversampled at increments of $128 \mathrm{~km}$ in each direction. The classifier then utilizes PDFs of LWP and the spatial variability of LWP obtained from spectral analysis to classify the low-cloud scenes into one of three Sc cloud categories based on the type of MCC. Further details of the cloud-type classification scheme are given in WH06 and references therein. We note that only cloudy MODIS scenes with marine low clouds not obscured by mid- and high-level clouds are included in the categorization procedure. Clear scenes or lowcloud scenes over land are excluded from this study. Also, it is emphasized that cloud retrievals based on MODIS radiances may be problematic at high latitudes due to the effect of low solar zenith angles and the possible presence of sea ice during the winter months. Therefore, low-cloud regions above and below about $65^{\circ} \mathrm{N}$ or $\mathrm{S}$ are excluded in the subsequent analysis.

Throughout this study, we use the output of this classification scheme as the basis for compositing A-train satellite observations by MCC type. In particular, we use radar backscatter data from the cloud profiling radar (CPR; Im et al., 2006) aboard CloudSat and returns from the Cloud-Aerosol Lidar with Orthogonal Polarization (CALIOP; Winker et al., 2007) aboard the CALIPSO satellite. CloudSat is a $94 \mathrm{GHz}$ nadirlooking cloud radar with a footprint of $1.5 \mathrm{~km}$ across track, $2.5 \mathrm{~km}$ along track and a sampling interval of $250 \mathrm{~m}$ in the vertical.

The cloud fraction of Sc clouds is determined by combining the CPR cloud mask with the cloud fraction within each CPR sampling volume seen by the lidar. The lidar cloud fraction within the CPR footprint is provided by the 2BGEOPROF-LIDAR product (Mace et al., 2009). The combination of radar and lidar observations for cloud detection and the computation of cloud fraction has significant benefits as it exploits the capabilities of both instruments in a 
synergistic way, i.e., the ability of the CPR to probe optically thick clouds and drizzle with the higher sensitivity of the lidar system in detecting optically thin clouds and tenuous cloud tops that are below the detection threshold of the CPR. Thus, the combination of cloud radar and lidar provides the best possible estimate of the occurrence of hydrometeor layers in the vertical column. Furthermore, the higher horizontal (approximately $1 \mathrm{~km}$ along track and $300 \mathrm{~m}$ across track) and vertical (approximately $75 \mathrm{~m}$ ) resolution of the lidar allows for an improved estimate of cloud fraction within the observed radar volume.

Because many partially cloudy radar volumes have a reflectivity near or below the detection threshold of the CPR of about $-30 \mathrm{dBZ}$ (Tanelli et al., 2008), the radar cloud mask is not simply a binary variable but includes confidence levels reflecting the degree of certainty that, for a given radar volume, the radar return is different from instrument noise (Marchand et al., 2008; Mace et al., 2009). Thus, for computing a radar-lidar cloud mask we closely follow Mace et al. (2009) and define a radar volume as cloudy if the CPR cloud mask is greater than or equal to 20 or the lidar cloud fraction within the CPR sampling volume is greater than or equal to $50 \%$. CPR volumes containing bad or missing data, ground clutter or weak returns with high probability of false positive detection are excluded. This approach yields an estimated probability for a false positive cloud detection of about $5 \%$ (Marchand et al., 2008).

We also use observations of shortwave and longwave irradiances provided by the Clouds and the Earth's Radiant Energy System (CERES) instrument aboard the Aqua satellite to estimate the cloud radiative effect of marine Sc clouds as a function of MCC type. In particular, we use the integrated CALIPSO CloudSat CERES and MODIS (CCCM) merged data set, which provides collocated instantaneous irradiance profiles along the CloudSat track. The CCCM data set contains CERES derived top-of-the-atmosphere (TOA) irradiances and vertical shortwave and longwave irradiance profiles that allow for computations of the radiative effect of low clouds. Further details of the CCCM product are given in Kato et al. (2010, 2011).

\section{Variability of marine low clouds and their morphologies}

The global distribution of annual mean low-cloud fraction determined from 5 years (2006-2011) of day and night time observations from active remote sensors aboard A-train satellites is shown in Fig. 2. Throughout this study, low clouds are defined as clouds with cloud top heights less than $3 \mathrm{~km}$, which is comparable to the $680 \mathrm{hPa}$ cloud top pressure threshold used to define low clouds in the International Satellite Cloud Climatology Project (ISCCP Rossow and Schiffer, 1991). Cloud top heights are inferred from combined CPR and CALIOP range gates.

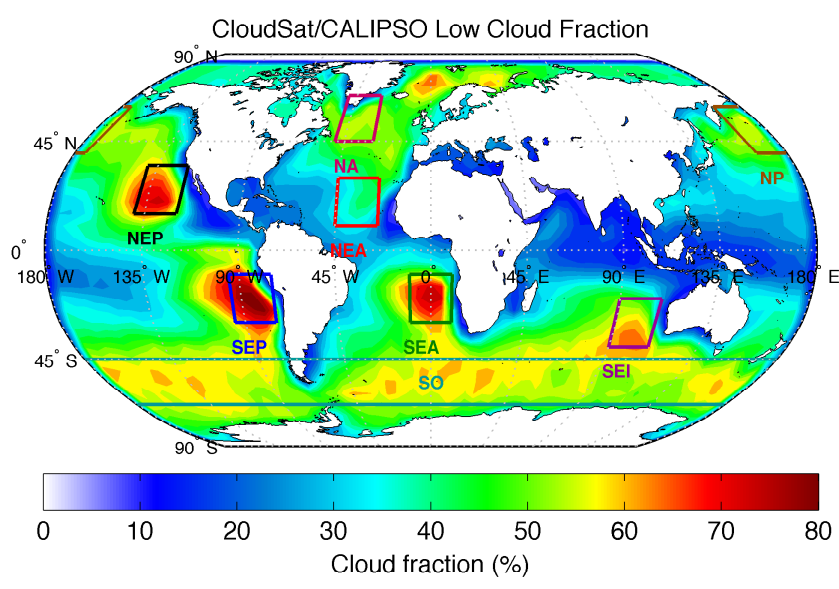

Figure 2. Global distribution of annually averaged low-cloud fraction from 5 years of CloudSat/CALIPSO data from 2006 to 2011. The colored rectangular boxes mark typical regions with persistent low-cloud amounts. The regions are Northeast Pacific (NEP), Southeast Pacific (SEP), Northeast Atlantic (NEA), Southeast Atlantic (SEA), Southeast Indian Ocean (SEI), North Atlantic (NA), North Pacific (NP) and Southern Ocean (SO). The locations of the displayed regions are adopted from Klein and Hartmann (1993) and are specified in Table 1.

The largest contributions to low-cloud fraction are found in subtropical regions in the eastern parts of oceans, west of continents and are typically associated with persistent decks of subtropical marine stratus (e.g., Klein and Hartmann, 1993). These subtropical regions are characterized by upwelling of cold ocean waters near the coast, strong subsidence in subtropical high-pressure systems and large values of lower tropospheric stability (LTS) caused by relatively cold sea surface temperatures (SSTs) and strong and sharp inversions at the top of the MBL.

However, considerable contributions to low cloudiness can also be found in the midlatitude storm tracks of both hemispheres and in the Arctic Ocean east of Greenland (i.e., the Greenland Sea). The rectangular boxes in Fig. 5 identify subtropical and midlatitude regions with high occurrences of low clouds. The geographical locations of these regions are adopted from Klein and Hartmann (1993) but modified such that the geographical boundaries now describe $20^{\circ} \times 20^{\circ}$ areas and better align with the approximate locations of low clouds in the 5-year CloudSat/CALIPSO climatology. The only exception is the Southern Ocean (SO) region, which is a $20^{\circ}$ broad strip around the globe. Details of the chosen study regions are given in Table 1.

The seasonal cycle of low-cloud fraction is shown in Fig. 3 for the various regions defined in Table 1. All subtropical low-cloud regions exhibit a pronounced seasonal cycle. The seasonal cycle tends to be stronger in the subtropical regions west of continents that have strong subtropical high-pressure systems and considerable upwelling of cold oceanic waters such as in the Southeast Pacific (SEP) and Southeast Atlantic 

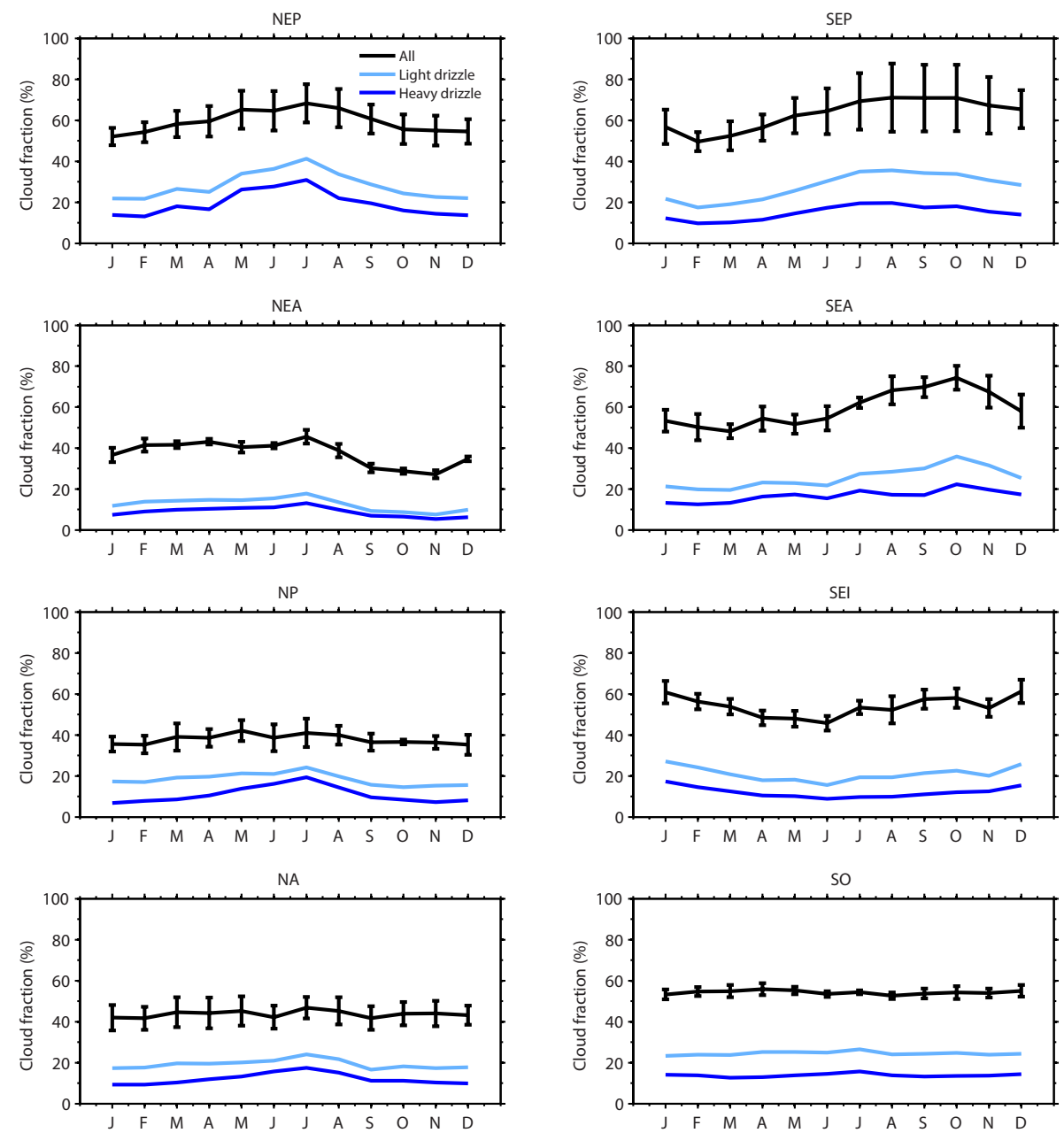

Figure 3. Seasonal cycle of cloud fraction for all low clouds (black) and low clouds with light (light blue) and heavy (dark blue) drizzle. Light and heavy drizzle conditions are categorized based on column maximum radar reflectivities with radar reflectivities in the range of -15 to $0 \mathrm{dBZ}$ for light drizzle and above $0 \mathrm{dBZ}$ for heavy drizzle. Each geographical region is shown in Fig. 2 and defined in Table 1 . Vertical bars indicate one standard deviation. Statistics are based on 5 years of Cloudsat/CALIPSO data.

(SEA). These regions have stronger seasonality in low clouds because of the strong seasonality in low-cloud controlling factors such as SST and LTS. In contrast, the seasonal cycle of low-cloud fraction is damped in the midlatitude storm track regions of the North Atlantic (NA) and North Pacific (NP) and almost absent in the Southern Ocean (SO).

Low-cloud fraction peaks during boreal summer (JJA) in the NEP and NEA regions but in austral spring (SON) in the SEP and SEA regions. Some of the differences in the seasonal cycle of low-cloud fraction may be explained by the response of the subtropical flow field to the coastal orography and its regional feedbacks on LTS (Richter and Mechoso, 2004). However, in the SEP there is also a considerable amount of low clouds during the boreal summer months (JJA) preceding the fall peak, with seasonally averaged lowcloud fraction only about $2 \%$ lower than during the fall season from September through November (SON). In the SEI,
Table 1. Definitions and geographical locations of study regions.

\begin{tabular}{ll}
\hline Region & Geographical boundaries \\
\hline Northeast Pacific (NEP) & $15-35^{\circ} \mathrm{N}, 120-140^{\circ} \mathrm{W}$ \\
Southeast Pacific (SEP) & $10-30^{\circ} \mathrm{S}, 75-95^{\circ} \mathrm{W}$ \\
Northeast Atlantic (NEA) & $10-30^{\circ} \mathrm{N}, 25-45^{\circ} \mathrm{W}$ \\
Southeast Atlantic (SEA) & $10-30^{\circ} \mathrm{S}, 10^{\circ} \mathrm{W}-10^{\circ} \mathrm{E}$ \\
North Pacific (NP) & $40-60^{\circ} \mathrm{N}, 165-185^{\circ} \mathrm{E}$ \\
Southeast Indian Ocean (SEI) & $20-40^{\circ} \mathrm{S}, 90-110^{\circ} \mathrm{E}$ \\
North Atlantic (NA) & $45-65^{\circ} \mathrm{N}, 30-50^{\circ} \mathrm{W}$ \\
Southern Ocean (SO) & $45-65^{\circ} \mathrm{S}, 180^{\circ} \mathrm{W}-180^{\circ} \mathrm{E}$ \\
\hline
\end{tabular}

maximum low-cloud coverage is found during the boreal winter months (DJF). Overall, the seasonal cycle of lowcloud fraction in subtropical regions is in good agreement 
Table 2. Low-cloud statistics derived from 5 years of combined CloudSat/CALIPSO observations. The seasons and cloud fractions given in parentheses are taken from Klein and Hartmann (1993) for comparison.

\begin{tabular}{|c|c|c|}
\hline Region & $\begin{array}{l}\text { Season and amount of } \\
\text { cloud fraction }\end{array}$ & $\begin{array}{l}\text { Season and amount of } \\
\text { max. min. cloud fraction }\end{array}$ \\
\hline Northeast Pacific (NEP) & JJA, $66 \%$ (JJA, $67 \%)$ & DJF, $54 \%$ (DJF, $45 \%)$ \\
\hline Southeast Pacific (SEP) & SON, $70 \%(\mathrm{SON}, 72 \%)$ & MAM $57 \%$ (DJF, $42 \%)$ \\
\hline Northeast Atlantic (NEA) & JJA, $42 \%$ (JJA, $35 \%$ ) & SON, $29 \%(\mathrm{SON}, 17 \%)$ \\
\hline Southeast Atlantic (SEA) & SON, $71 \%(\mathrm{SON}, 75 \%)$ & MAM, $51 \%($ MAM, $48 \%)$ \\
\hline North Pacific (NP) & MAM, $40 \%(\mathrm{JJA}, 82 \%)$ & DJF, $35 \%$ (DJF, $54 \%)$ \\
\hline Southeast Indian Ocean (SEI) & DJF, $59 \%$ (DJF, $45 \%)$ & MAM, $50 \%$ (JJA, $41 \%)$ \\
\hline North Atlantic (NA) & JJA, $45 \%$ (JJA, $68 \%)$ & DJF, $42 \%$ (DJF, $51 \%$ ) \\
\hline Southern Ocean (SO) & MAM, $55 \%$ (DJF, $62 \%)$ & JJA, $53 \%(?, ?)$ \\
\hline
\end{tabular}

with the climatology of marine stratus compiled from shipbased observations by Klein and Hartmann (1993).

At northern midlatitudes, the seasonal cycle is considerably damped but exhibits slightly higher amounts of low cloudiness during boreal spring and summer than during the fall and winter months. Over the SO, low-cloud cover is almost constant at around $54 \%$. Overall, the largest amounts of low clouds, up to approximately $70-75 \%$ cloud fraction, are found in the subtropics, in particular in the NEP during boreal summer months and in the SEP and SEA during austral spring. The highest annually averaged low-cloud fractions are on the order of about $60 \%$ and are found in the subtropical marine stratus regions of the SEP, NEP and NEA as well as at midlatitudes within the SO. In contrast, the lowest annually averaged low-cloud fractions are found in the NEA with only about $37 \%$.

The cloud fraction contributed by low clouds with light and heavy drizzle tracks the overall low-cloud fraction in all regions as shown in Fig. 3. The classification of low clouds with significant amount of drizzle is based on the column maximum radar reflectivity $Z_{\max }$ observed by the CPR. Here, lightly and heavily drizzling clouds are defined as low clouds with column maximum radar reflectivity in the range of $-15 \mathrm{dBZ} \leq Z_{\max }<0 \mathrm{dBZ}$ and $Z_{\max } \geq 0 \mathrm{dBZ}$, respectively. The regions with the largest contributions of low and drizzling clouds are again the NEP, SEP and SEA with drizzling low-cloud fractions up to almost $40 \%$, which is in reasonable agreement with previous satellite-based estimates (Leon et al., 2008).

Previous studies have suggested that the occurrence and persistence of marine low clouds is fundamentally linked to the static stability of the lower troposphere (e.g., Klein and Hartmann, 1993; Wood and Bretherton, 2006). The seasonal cycles of lower tropospheric stability (LTS) and estimated inversion strength (EIS) are shown in Fig. 4 for each region. LTS is defined as the difference in potential temperature between the $700 \mathrm{hPa}$ pressure level and the surface such that

$\mathrm{LTS}=\theta\left(\mathrm{p}_{700}, \mathrm{~T}_{700}\right)-\theta\left(\mathrm{p}_{\mathrm{s} 1}, \mathrm{~T}_{\mathrm{s} 1}\right)$ with $\left(p_{700}, p_{\mathrm{sl}}\right)$ and $\left(T_{700}, T_{\mathrm{sl}}\right)$ the pressure and temperature at the $700 \mathrm{hPa}$ pressure level and sea level, respectively. Following Wood and Bretherton (2006) EIS is defined such that

$\mathrm{EIS}=\mathrm{LTS}-\Gamma_{\mathrm{m}}^{850}\left(\mathrm{z}_{700}-\mathrm{LCL}\right)$.

The moist-adiabatic potential temperature gradient $\Gamma_{\mathrm{m}}^{850}$ is computed using the arithmetic mean of the temperature at sea level and the temperature at the $700 \mathrm{hPa}$ pressure level $\Gamma_{\mathrm{m}}^{850}=\Gamma_{\mathrm{m}}\left(\left[T_{\mathrm{sl}}+T_{700}\right] / 2\right) . \Gamma_{\mathrm{m}}$ can be calculated as

$\Gamma_{\mathrm{m}}(T, p)=\frac{g}{c_{\mathrm{p}}}\left[1-\frac{1+L_{\mathrm{v}} q_{\mathrm{s}}(T, p) / R_{\mathrm{d}} T}{1+L_{\mathrm{v}}^{2} q_{\mathrm{s}}(T, p) / c_{\mathrm{p}} R_{\mathrm{v}} T^{2}}\right]$,

where $L_{\mathrm{v}}$ is the latent heat of vaporization; $q_{\mathrm{s}}(T, p)$ is the saturation mixing ratio; $R_{\mathrm{d}}$ and $R_{\mathrm{V}}$ are the specific gas constants for dry air and water vapor, respectively; $g$ is the gravitational acceleration; and $c_{\mathrm{p}}$ is the specific heat of air at constant pressure. To calculate $z_{700}$, little error is introduced by assuming an exponential decrease in pressure with height with a single scale height (Wood and Bretherton, 2006):

$z_{700}=\frac{R_{\mathrm{d}} T_{\mathrm{sl}}}{g} \ln \left(\frac{p_{\mathrm{sl}}}{700 \mathrm{hPa}}\right)$.

The lifting condensation level (LCL) is computed following the procedure outlined in Bolton (1980). The thermodynamic fields needed for the computation of LTS and EIS are taken from 5 years of data from the ECMWF-AUX CloudSat product.

Generally, there is a good correlation between LTS or EIS and the amount of low clouds in the subtropics although for some regions the correlation exhibits a considerable lag (Fig. 4 and Table 3). For example, in the NEP, LTS and EIS peak in June, whereas the maximum amount of low cloudiness is reached in July. This lagged correlation suggests that high LTS or EIS is a necessary condition for maintaining low clouds at the subtropics, but high values of static stability are not the only component controlling the seasonal variability of marine low-cloud fraction. Also, the correlation between LTS or EIS and low cloudiness is weaker at 

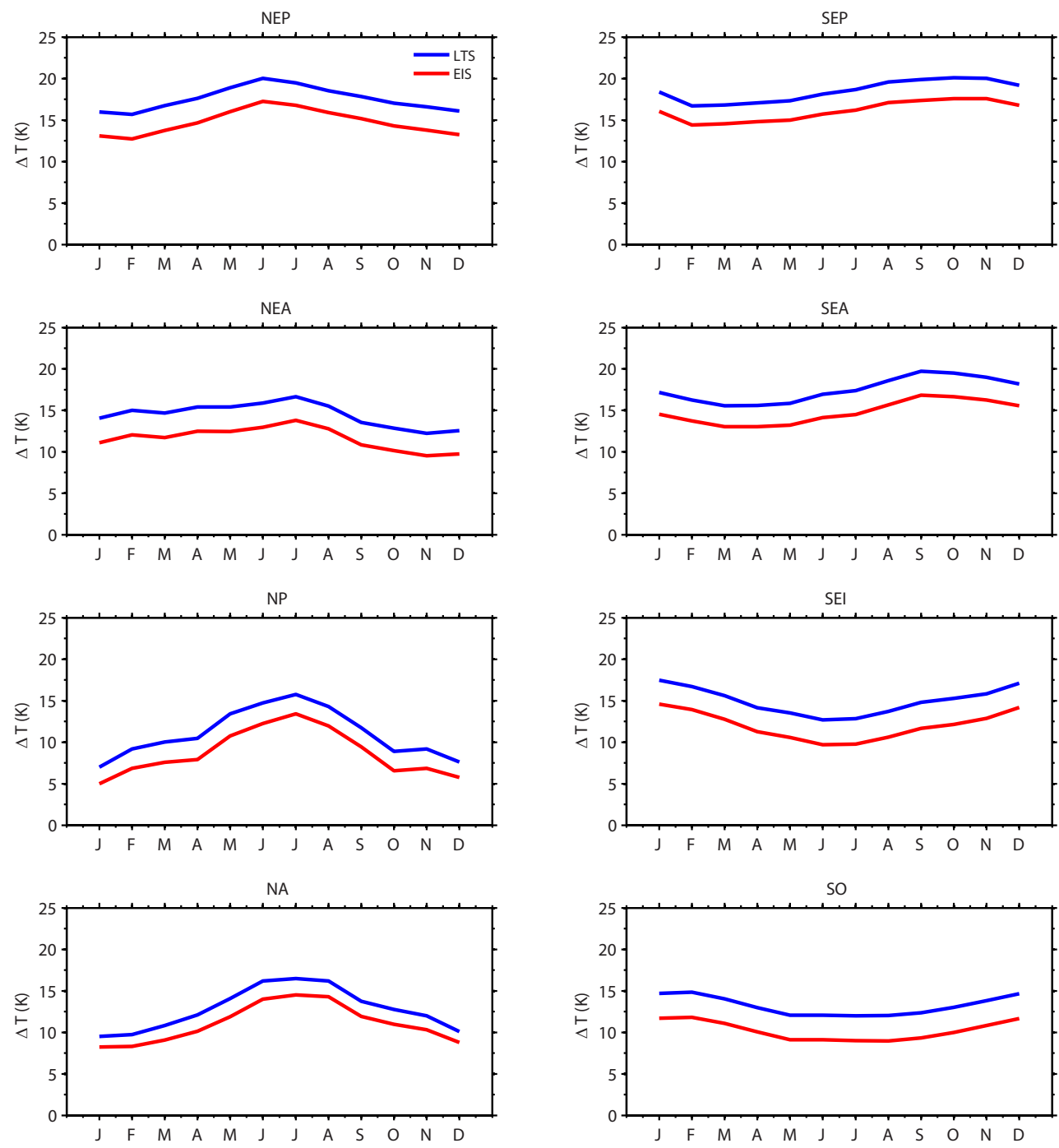

Figure 4. Same as Fig. 3 but for lower tropospheric stability (LTS, blue) and estimated inversion strength (EIS, red). Statistics are based on 5 years of data from the ECMWF-AUX CloudSat product.

midlatitudes and even breaks down in the SO (Fig. 4 and Table 3). A possible explanation for the low correlations between LTS or EIS and low-cloud amount at midlatitudes is that the interannual variability is controlled by both SST and free-tropospheric temperature, and there is evidence suggesting that the free-tropospheric interannual variability may be the dominant driver in some regions (Stevens et al., 2007). Also, the correlation between LTS or EIS and cloud fraction is weaker on shorter timescales as suggested by Zhang et al. (2009). However, the limited validity of these relationships can, at least in part, also be explained by the different morphologies of marine low clouds (e.g., open MCC, closed MCC) that can coexist under very similar environmental conditions but considerably affect the overall cloud fraction of regions, which is discussed next.
Table 3. Annual means of lower tropospheric stability (LTS) and estimated inversion strength (EIS) as well as the correlation coefficients between low-cloud fraction from CloudSat/CALIPSO and LTS $\left(r_{\text {CF,LTS }}\right)$ and EIS $\left(r_{\text {CF,EIS }}\right)$. All values are derived from 5 years of data from the CloudSat ECMWF-AUX product.

\begin{tabular}{lllll}
\hline Region & $\begin{array}{l}\text { LTS } \\
(\mathrm{K})\end{array}$ & $r_{\text {CF,LTS }}$ & $\begin{array}{l}\text { EIS } \\
(\mathrm{K})\end{array}$ & $r_{\text {CF,EIS }}$ \\
\hline Northeast Pacific (NEP) & 18 & 0.94 & 15 & 0.94 \\
Southeast Pacific (SEP) & 18 & 0.88 & 16 & 0.87 \\
Northeast Atlantic (NEA) & 14 & 0.90 & 12 & 0.88 \\
Southeast Atlantic (SEA) & 17 & 0.92 & 15 & 0.91 \\
North Pacific (NP) & 11 & 0.82 & 9 & 0.80 \\
Southeast Indian Ocean (SEI) & 15 & 0.81 & 12 & 0.78 \\
North Atlantic (NA) & 13 & 0.50 & 11 & 0.48 \\
Southern Ocean (SO) & 13 & 0.22 & 10 & 0.23 \\
\hline
\end{tabular}



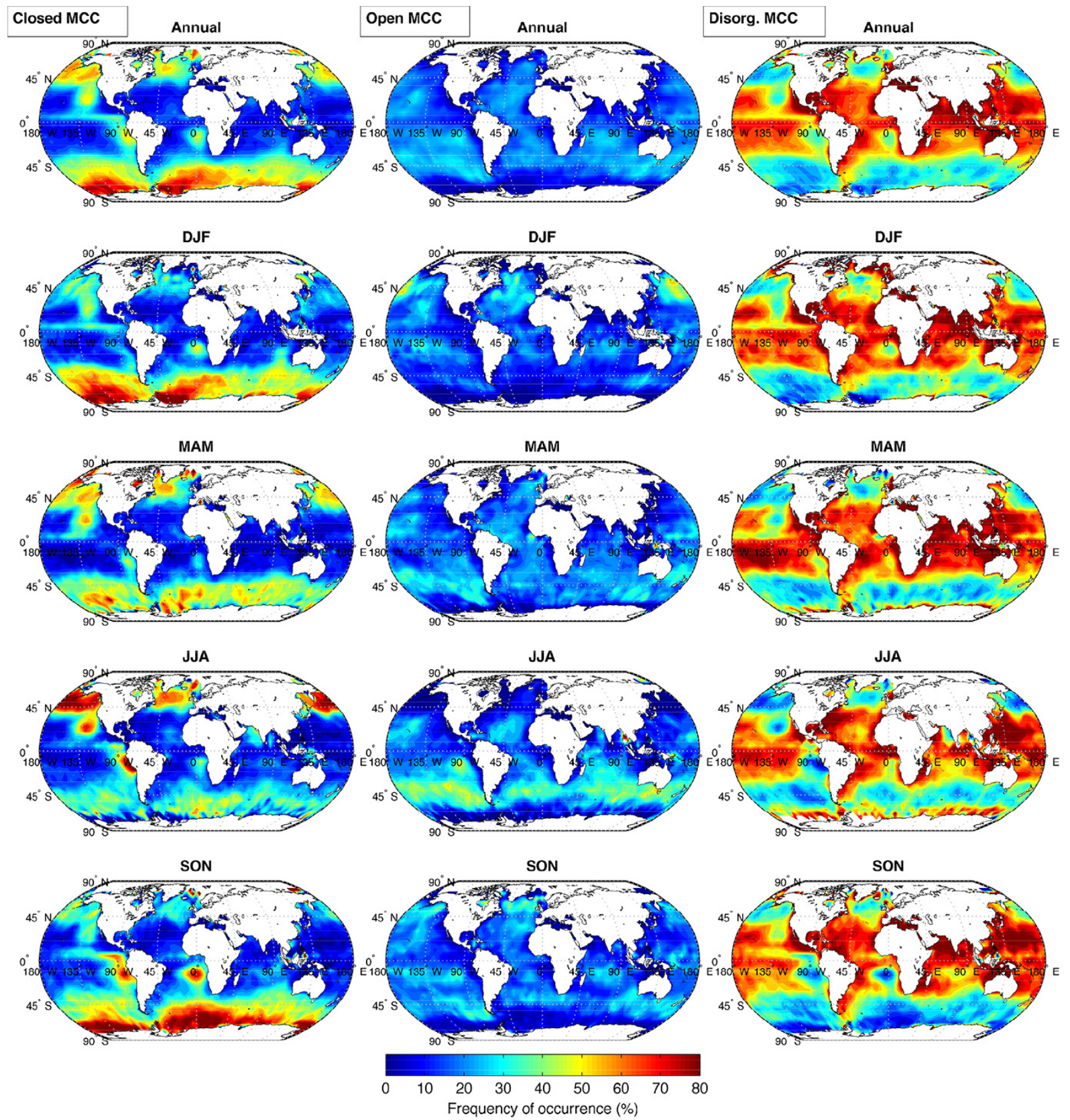

Figure 5. Global distribution of the frequency of occurrence of MCC types based on 1 year of MODIS Aqua observations from 2008. Shown are closed MCC (left), open MCC (center) and cellular but disorganized MCC (right). Seasonal means are shown for winter (DJF), spring (MAM), summer (JJA) and fall (SON). All MCC observations are binned into $5^{\circ} \times 5^{\circ}$ regions. The frequency of occurrence is the fraction of occurrences of a certain MCC type to the total number of all MCC occurrences expressed as a percentage value. Regions with no data are shown in white.

Figure 5 shows global distributions of the frequency of occurrence of MCC types for a full year of MODIS Aqua observations from 2008 both annually averaged and as a function of season. All MCC observations are binned into $5^{\circ} \times 5^{\circ}$ regions. In each grid box, the frequency of occurrence is the fraction of occurrences of a certain MCC type to the total number of all MCC occurrences expressed as a percentage value. Generally, the frequency of occurrence of closed MCC tends to increase towards higher latitudes, whereas cellular but disorganized MCC types tend to increase at lower latitudes. In contrast, organized open MCC types exhibit less latitudinal dependence than the other MCC types but tend to maximize in subtropical regions of both hemispheres. Frequency of occurrences of closed MCC types 

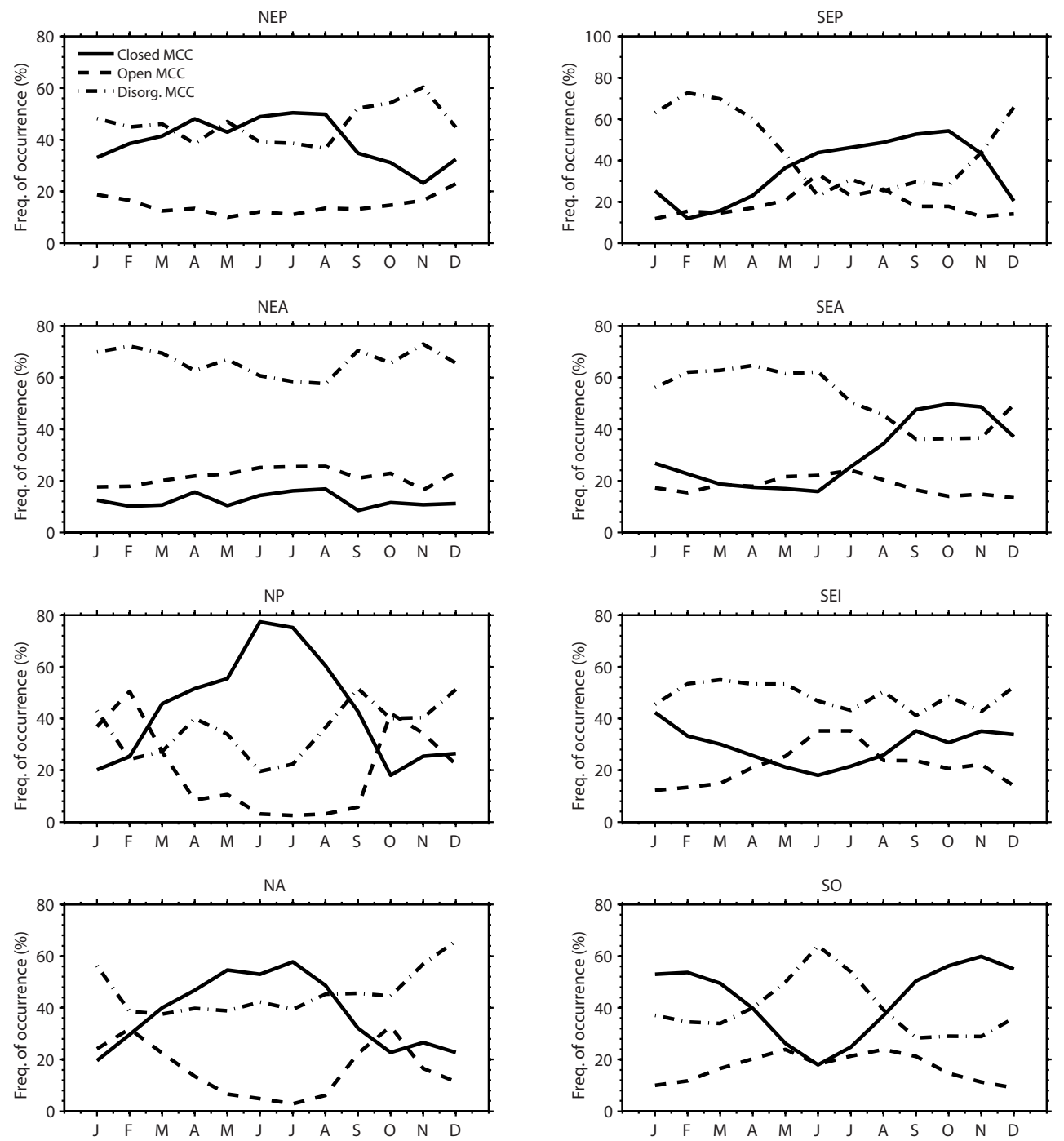

Figure 6. Same as Fig. 3 but for the seasonal cycle of the frequency of occurrence of MCC types. Shown are closed MCC (solid), open MCC (dashed) and cellular but disorganized MCC (dash-dotted).

exhibit maxima at midlatitude storm tracks between 45 and $60^{\circ} \mathrm{N}$ in the Northern Hemisphere and between 45 and $65^{\circ} \mathrm{S}$ in the Southern Hemisphere. Closed MCC are also the dominant type of low-cloud morphology in the Arctic Ocean east of Greenland (i.e., the Greenland Sea). However, this result should be taken with caution due to the inherent uncertainty in MODIS cloud retrievals (i.e., cloud optical depth and effective radius) at high latitudes mentioned in Sect. 2. Secondary maxima are found in subtropical regions roughly between 10 and $30^{\circ} \mathrm{S}$ in the eastern parts of the Pacific and Atlantic oceans and between about 20 and $40^{\circ} \mathrm{N}$ in the Northeast Pacific. Notably, there is also clear indication of closed MCC types over the equatorial cold tongue in the eastern equatorial Pacific, especially during boreal winter (SON). Open MCC types exhibit the lowest frequency of occurrence of all low-cloud morphologies. In subtropical regions, the closed MCC types occur most frequently in near-coastal waters, whereas open MCCs are more likely to occur further offshore (e.g., west of $90^{\circ} \mathrm{W}$ in the SEP and west of $135^{\circ} \mathrm{W}$ in the NEP). The higher frequency of occurrence of open MCCs maximizes west of subtropical high-pressure systems as these regions feature warmer SSTs and a deeper and less stable MBL (Stevens, 2000; Wyant et al., 1997). Cellular but disorganized MCCs are the predominant type of marine low clouds in regions with warm SST, in particular in the tropics and trade wind zones.

A considerable seasonal cycle is found for closed and open MCC, whereas the occurrence frequency of cellular but disorganized MCCs shows relatively little interseasonal variability. At midlatitudes a maximum in the frequency of occurrence of closed MCC is found during boreal summer (JJA) in the Northern Hemisphere and austral summer (DJF) 
in Southern Hemisphere. Similarly, in the subtropics, closed MCC occurrences exhibit a clear seasonal cycle with occurrences peaking in summer (NEP) and fall (SEP), respectively. Open MCCs tend to peak in boreal winter at midlatitudes, in particular over the western parts of the Pacific, and over vast parts of midlatitude southern oceans during boreal summer. The seasonality in the open MCC occurrence may be linked to the frequency of occurrence of cold-air outbreaks and the associated advection of cold continental air masses over warmer ocean surfaces in the wake of cyclones, which are more likely during winter months. However, there is also a clear peak in the frequency of occurrence of open MCC in the SEP region west of about $90^{\circ} \mathrm{W}$ during boreal summer (JJA). Cellular but disorganized MCCs show a considerably lower seasonal cycle as they are most frequently found over tropical oceans and trade wind regions, which exhibit lower interannual variability.

Figure 6 shows the seasonal cycle of different MCC types for each region shown in Fig. 2. Similar to low-cloud fraction and LTS, there is a pronounced seasonal cycle in low-cloud morphologies. In general, organized closed-cellular MCC and cellular but disorganized MCC are the dominant lowcloud morphology for almost all regions and seasons. For the subtropical regions, the amount of low cloudiness is well correlated with the occurrence frequency of closed-cellular MCCs, which peaks in the same season as low-cloud fraction. Also, there is an anticorrelation between closed MCCs and disorganized MCCs, which suggests that as LTS declines the low clouds are more likely to transition from organized closed-cellular MCC types to cellular but disorganized MCCs. The contributions of open MCC are considerably lower with frequency of occurrences ranging from about 10 to $30 \%$. Interestingly, the most prevalent MCC types in the NEA are disorganized and open MCC with little contributions from closed MCC. Thus, the relatively small value of low cloudiness in the NEA may be explained by the small contributions from closed MCC types, which are less common in this region. The most frequent occurrences of open MCCs in the subtropics are found in the SEI during boreal summer and during boreal fall and winter in the NA and NP. At midlatitudes, the frequency of occurrence of closed MCCs maximizes during boreal summer in the NP and NA and during austral summer in the SO. Open MCC contributions peak during boreal winter in the NP and NA and during austral winter in the SO. The seasonality and strong anticorrelation between closed and open MCC types at midlatitudes suggests that open MCC types are more frequently found during winter months, when stronger cyclonic activity leads to more frequent cold-air outbreaks. Table 4 lists the frequency of occurrence and cloud fraction for each region and MCC type.

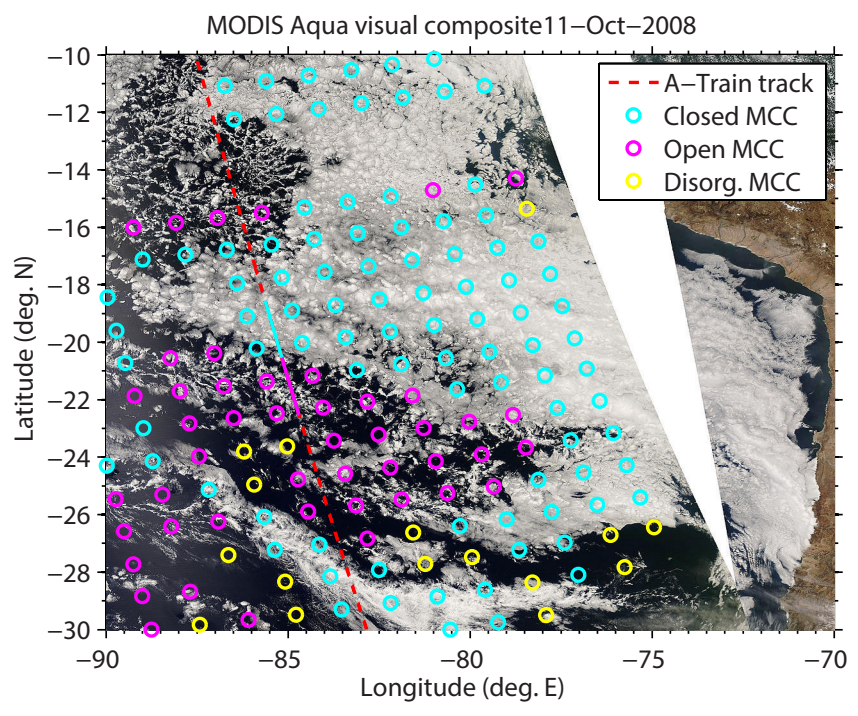

Figure 7. Composite of MODIS Aqua visual imagery for the 11 October 2008 case study in the SEP. Shown are the A-train track (dashed red line) and the MCC types identified by the ANN for each $256 \times 256 \mathrm{~km}^{2}$ cloud scene (colored circles) along the MODIS swath. The colored lines mark the sections along the A-train track classified as closed MCC (cyan), open MCC (magenta), and cellular but disorganized MCC (yellow) as an example. The MODIS image resolution is $2 \mathrm{~km}$.

\section{Case study}

In order to derive reliable statistics of the effects of different MCC types on the microphysical properties and radiative effects of low clouds, A-train observation are mapped onto the MCC type classification based on MODIS cloud scene data as discussed in Sect. 2. Here, we briefly explain the mapping process in the context of a case study. The case study is shown Fig. 7 and depicts a field of marine Sc clouds in the SEP sampled by A-train satellites on 11 October 2008. A wide patch of Sc clouds with closed MCC type stretches out from close to the Chilean shore to almost $90^{\circ} \mathrm{W}$. The Sc cloud deck with closed MCC transitions to open MCC along the A-train track just south of about $20^{\circ} \mathrm{S}$ and north of about $15^{\circ} \mathrm{S}$.

For a given cloud scene in the MODIS swath, the mapping of CloudSat and CERES observations is based on the geolocation and time of observation of each MCC scene. A geometric mapping algorithm is used to associate each CPR profile with the MODIS cloud scenes on either side of the A-train track. Overall, the MCC type classification and mapping of A-train observations is reasonably accurate but is limited primarily by a statistical false detection rate of approximately $10-15 \%$ inherent to the neural network algorithm as discussed in WH06.

By examining the A-train instrument retrievals for this case study, we find that the closed and open MCC regions exhibit striking differences in terms of their microphysical and 
Table 4. Annually averaged cloud fraction and frequency of occurrence of MCC for each region defined in Table 1. The statistics are based on 1 year of data from 2008 .

\begin{tabular}{|c|c|c|c|}
\hline Region & MCC type & $\begin{array}{l}\text { Cloud } \\
\text { fraction }(\%)\end{array}$ & $\begin{array}{l}\text { Frequency of } \\
\text { occurrence }(\%)\end{array}$ \\
\hline \multirow[t]{3}{*}{ Global } & Closed & 90 & 28 \\
\hline & Open & 51 & 15 \\
\hline & Disorg. & 40 & 58 \\
\hline \multirow[t]{3}{*}{ Northeast Pacific (NEP) } & Closed & 93 & 40 \\
\hline & Open & 60 & 15 \\
\hline & Disorg. & 49 & 46 \\
\hline \multirow[t]{3}{*}{ Southeast Pacific (SEP) } & Closed & 91 & 35 \\
\hline & Open & 54 & 19 \\
\hline & Disorg. & 43 & 46 \\
\hline \multirow[t]{3}{*}{ Northeast Atlantic (NEA) } & Closed & 84 & 12 \\
\hline & Open & 42 & 22 \\
\hline & Disorg. & 34 & 66 \\
\hline \multirow[t]{3}{*}{ Southeast Atlantic (SEA) } & Closed & 90 & 30 \\
\hline & Open & 55 & 18 \\
\hline & Disorg. & 46 & 52 \\
\hline \multirow[t]{3}{*}{ North Pacific (NP) } & Closed & 91 & 21 \\
\hline & Open & 61 & 15 \\
\hline & Disorg. & 49 & 36 \\
\hline \multirow[t]{3}{*}{ Southeast Indian Ocean (SEI) } & Closed & 91 & 29 \\
\hline & Open & 55 & 22 \\
\hline & Disorg. & 44 & 49 \\
\hline \multirow[t]{3}{*}{ North Atlantic (NA) } & Closed & 90 & 38 \\
\hline & Open & 63 & 16 \\
\hline & Disorg. & 55 & 46 \\
\hline \multirow[t]{3}{*}{ Southern Ocean (SO) } & Closed & 91 & 44 \\
\hline & Open & 58 & 17 \\
\hline & Disorg. & 52 & 40 \\
\hline
\end{tabular}

radiative characteristics as shown in Fig. 8. The closed and open MCC regions exhibit pronounced differences in terms of cloudiness and radar reflectivity. The closed MCC region is characterized by a relatively continuous and almost completely overcast cloud deck with average cloud fraction close to $100 \%$. In contrast, the open MCC region exhibits cellular cloud patterns intermitted by cloud-free regions and average cloud fractions of about $75 \%$.

The column maximum reflectivities $Z_{\max }$ from the CPR and cloud base rain rates $R_{\mathrm{cb}}$ are considerably higher but also more variable in the open $\mathrm{MCC}$ region than in the closed MCC region. Here, approximate rain rates at Sc cloud base are computed from the radar backscatter data by inverting the $Z-R$ power law relationship

$Z=25 R^{1.3}$,

with the rain rate $R$ given in units of $\mathrm{mm} \mathrm{h}^{-1}$ and $Z$ the radar reflectivity factor given in units of $\mathrm{mm}^{6} \mathrm{~m}^{-3}$. This $Z-R$ relationship has been found appropriate for subtropical marine Sc clouds (Comstock et al., 2004) and we apply it consistently to all marine low clouds in our study. However, we emphasize that $Z-R$ relationships are inherently uncertain and may induce considerable errors due to uncertainties in the microphysics (e.g., drop size distributions) and differences in the environmental conditions (e.g., vertical velocities). The column maximum radar reflectivities are about 10 $15 \mathrm{dBZ}$ higher in the boundary cells within regions of open MCC than anywhere else in the closed MCC region. The column maximum radar reflectivities suggest that drizzle rates are higher but also spatially more localized in open MCCs than in closed MCCs and, in fact, cloud base drizzle rates are about an order of magnitude higher in the open cells than in the closed cells. There is also indication of a boundary cell at the edge of the transition region between closed MCC and open MCC with slightly higher radar reflectivities than the rest of the closed MCC region. These boundary cells are also found in aircraft radar data collected during the VOCALS campaign (Wood et al., 2011).

Besides the differences in the low-cloud fraction and precipitation characteristics, the open and closed MCC regions also differ considerably in terms of the instantaneous reflected shortwave radiation and TOA cloud radiative forcing (CRF). Throughout this study, TOA CRF is defined as the difference in radiative fluxes between clear-sky and cloudy 

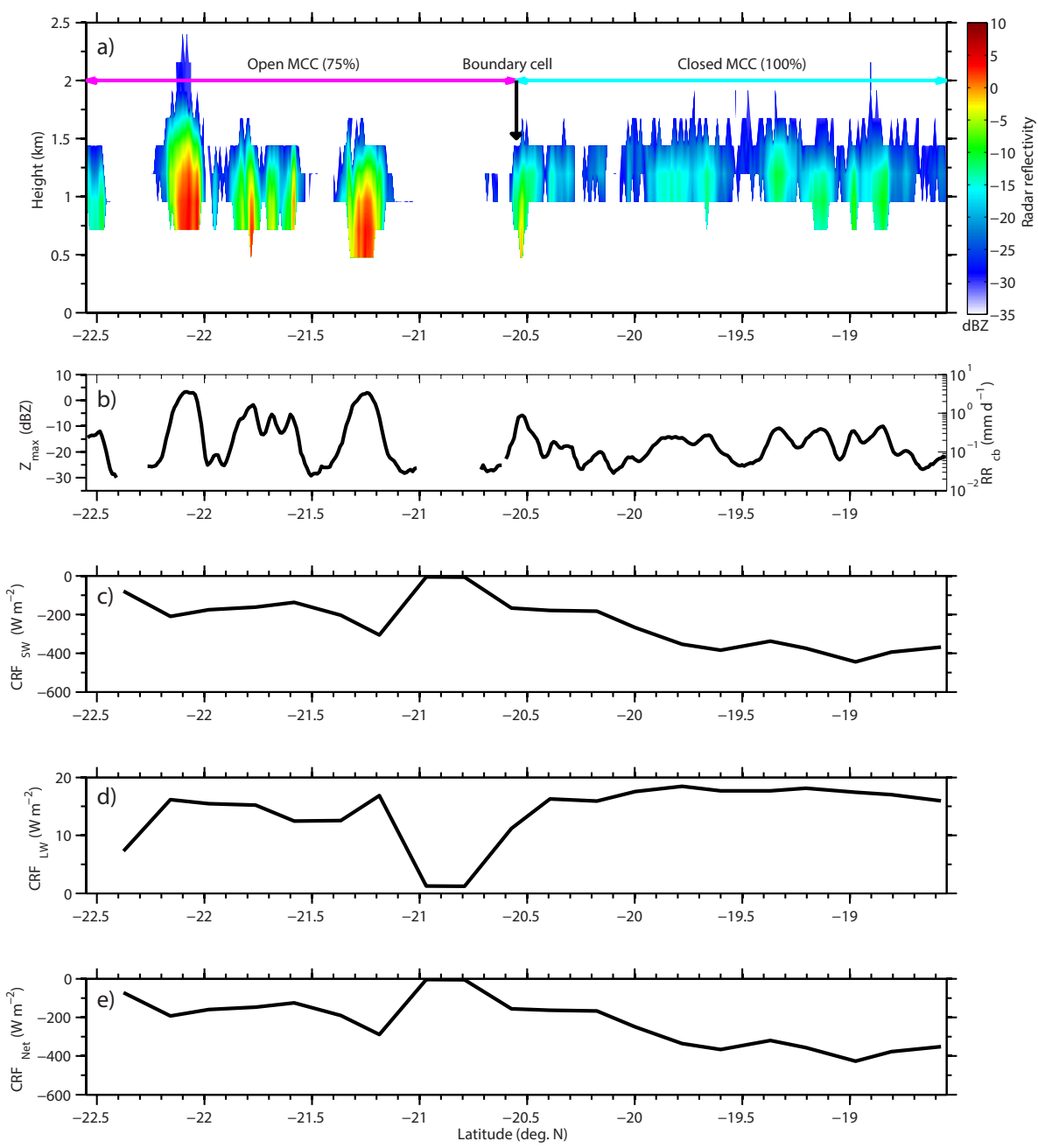

Figure 8. Vertical profiles of CloudSat CPR reflectivity for a selected region showing a transition from closed to open MCC (a), column maximum radar reflectivity $Z_{\max }$ and associated rain rates $R_{\mathrm{cb}}$ at cloud base (b), CERES shortwave cloud radiative forcing (CRF) (c), longwave CRF (d) and net (shortwave and longwave) CRF (e).

conditions (e.g., Hartmann et al., 1986) and is computed from the radiative fluxes observed by CERES. Due to the lower fraction of cloudiness in the open MCC region, the amount of reflected shortwave radiation is lower than in the closed MCC region. As a consequence, the averaged instantaneous shortwave CRF is about twice as high in the closed MCC region $\left(-400 \mathrm{~W} \mathrm{~m}^{-2}\right)$ than in the open MCC region $\left(-200 \mathrm{~W} \mathrm{~m}^{-2}\right)$. However, the OLR is about the same for both regions and results in a slightly positive longwave CRF (approximately $15 \mathrm{~W} \mathrm{~m}^{-2}$ ), which is typical for low clouds. As expected, the net CRF is dominated by the shortwave CRF and is strongly negative and larger for the closed MCC region than for the open MCC region.

\section{Microphysical and macrophysical properties}

In the subsequent section statistical properties of the cloud and precipitation characteristics of marine low clouds are examined for the various MCC types and regions. All statistics are based on 1 year of combined MODIS and CloudSat/CALIPSO observations from 2008.

\subsection{Cloud fraction}

Figure 9 shows the variability of low-cloud fraction as a function of the MCC type and annually averaged values of cloud fraction for the different MCC types in each study region are given in Table 4. As expected from previous studies and our case study from Sect. 4, the cloud fraction of lowcloud fields is highly variable and a function of the MCC type. On a global scale, the cloud fraction is largest for closed MCC, with a mean cloud fraction of about $90 \%$. The cloud 

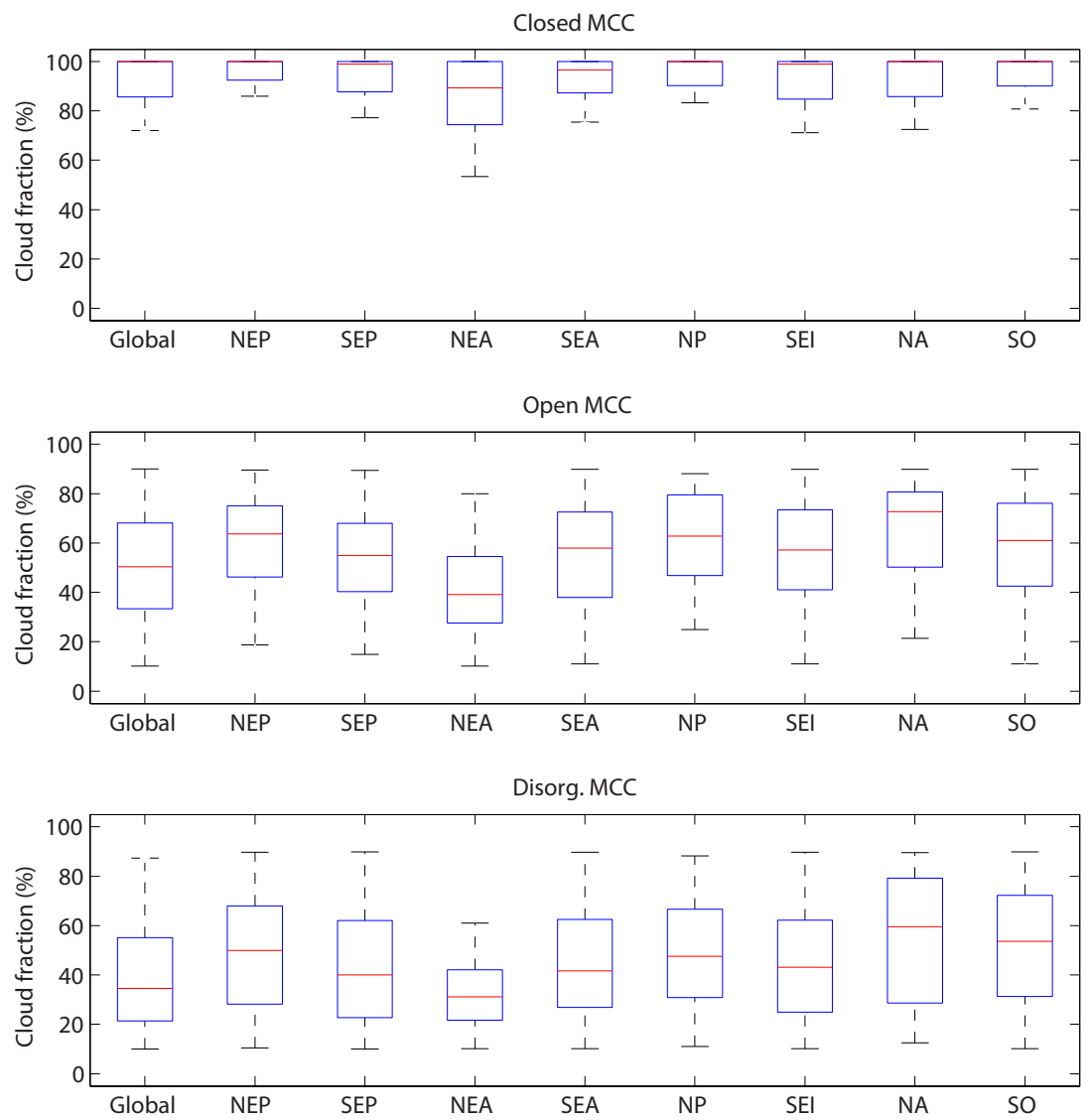

Figure 9. Box-and-whisker plots of cloud fraction for each MCC category. The median value is shown as a red horizontal line, boxes indicate the interquartile range (25th to 75th percentile) and the whiskers extend to $\pm 2 \sigma$ of the standard normal distribution.

fractions are lower for open MCCs and lowest for cellular but disorganized MCCs with mean cloud fractions of about 51 and $40 \%$, respectively (see Table 4). However, it is noted that the distributions of cloud fractions are heavily skewed in all cases with modest regional variability. For example, in most study regions, the median annually averaged cloud fraction for low clouds with closed MCC characteristics is close to $100 \%$, whereas the mean value is only about $90 \%$. Cloud fractions for closed MCCs tend to be highest in the NEP and lowest in the NEA. The differences in mean cloud fraction for closed MCC in the NEP and NEA are statistically significant based on the nonparametric Wilcoxon rank-sum test (Wilks, 2006) with $95 \%$ confidence level. Similarly, mean cloud fractions for open MCCs and cellular but disorganized MCCs are quite variable depending on the region, with averaged values broadly ranging from 40 to $60 \%$ for open MCCs and 40 to $50 \%$ for cellular but disorganized MCCs (see Table 4).

\subsection{Radar reflectivities and cloud base rain rates}

PDFs of column maximum radar reflectivity $Z_{\max }$ in marine Sc clouds seen by the CPR are shown in Fig. 10 for the global data and in Fig. 12 for the various subtropical and midlatitude regions defined in Table 1 . The PDFs of $Z_{\max }$ indicate fundamental differences in the cloud and precipitation characteristics of Sc clouds depending on the type of MCC. Since the column maximum radar reflectivity $Z_{\max }$ for drizzling clouds (i.e., $Z_{\max } \geq-15 \mathrm{dBZ}$ ) is typically found close to the cloud base (Comstock et al., 2004), $Z_{\max }$ is a good indicator for the precipitation rate at cloud base $\left(\mathrm{RR}_{\mathrm{CB}}\right)$. $\mathrm{A} Z-R$ power law relationship appropriate for marine Sc clouds is used to infer $R_{\mathrm{cb}}$ from $Z_{\max }$ using a threshold radar reflectivity of $Z_{\max }=-15 \mathrm{dBZ}$ for the definition of drizzle as detailed in Sect. 4.

In most regions, the probability of observing no significant $\left(Z_{\max }<-15 \mathrm{dBZ}\right)$ or light drizzle $\left(-15 \mathrm{dBZ} \leq Z_{\max }<\right.$ $0 \mathrm{dBZ})$ is higher in clouds with closed MCC than in Sc clouds with open or disorganized MCC types. In contrast, the probability of observing moderate or heavy drizzle $\left(Z_{\max } \geq\right.$ $0 \mathrm{dBZ}$ ) is greater for clouds with open MCC than for clouds with closed or disorganized MCCs. About $70 \%$ of the columns sampled by the CPR in regions with closed MCC have $Z_{\max }>-15 \mathrm{dBZ}$ and thus have significant amounts of drizzle, whereas about $40 \%$ of the columns with closed MCCs have $Z_{\max } \geq 0 \mathrm{dBZ}$ and therefore are moderately to 

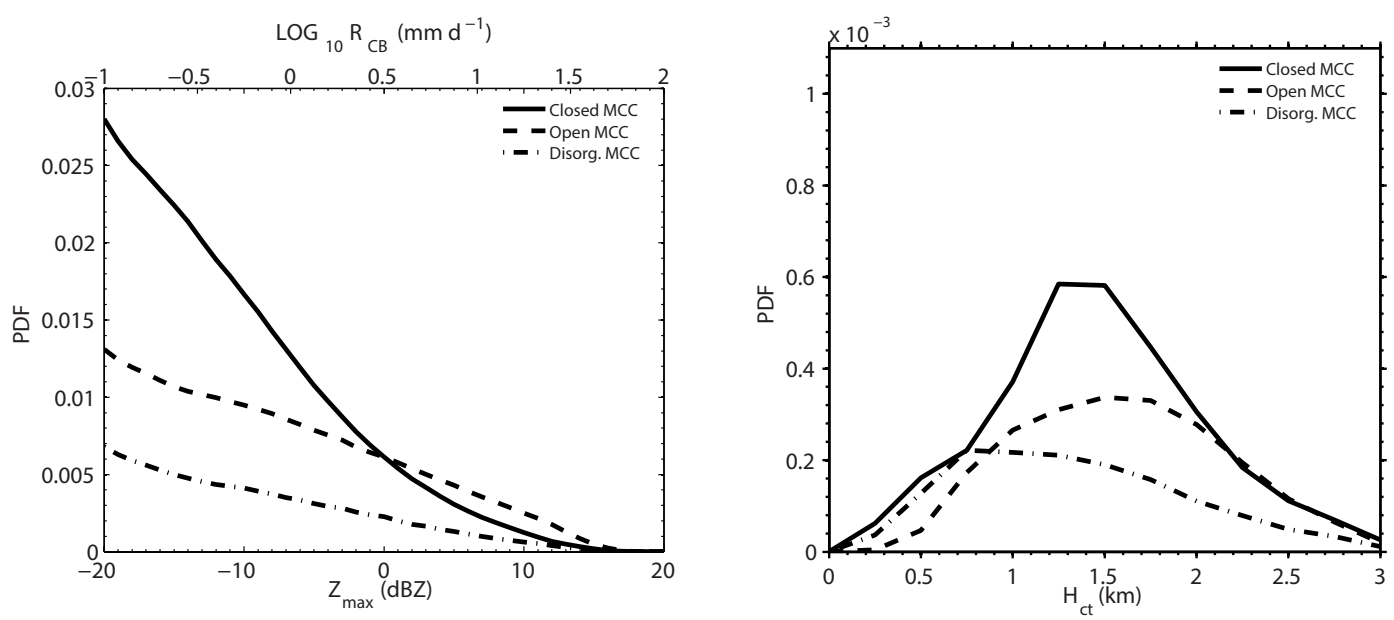

Figure 10. PDFs of column maximum radar reflectivity $Z_{\max }$ (left) and cloud top height $H_{\mathrm{ct}}$ (right) for low clouds with closed (solid), open (dashed) and cellular but disorganized (dash-dotted) MCC types. All PDFs are based on global data. The median cloud top height is $1460 \mathrm{~m}$ for closed MCC, $1570 \mathrm{~m}$ for open MCC and $1300 \mathrm{~m}$ for cellular but disorganized MCC.

heavily drizzling. The fraction of closed MCC columns with significant amount of drizzle exhibits regional variability and is somewhat higher in subtropical regions (e.g., NEP, SEP, SEA) than at midlatitudes. For regions with open MCC, about $40 \%$ of the columns have maximum radar echoes above $Z_{\max }>-15 \mathrm{dBZ}$ and approximately $30 \%$ contain $Z_{\max } \geq 0 \mathrm{dBZ}$. Disorganized MCC have column maximum radar echoes above $Z_{\max }>-15 \mathrm{dBZ}$ about $30 \%$ of the time and $Z_{\max } \geq 0 \mathrm{dBZ}$ about $20 \%$ of the time. In most regions the PDFs of $Z_{\max }$ decrease monotonically with increasing $Z_{\max }$, with exceptions in the North Atlantic (NA) and the North Pacific (NP), where $Z_{\max }$ exhibits a local maxima somewhere between 0 and $-10 \mathrm{dBZ}$. The occurrence of a peak in the PDFs of $Z_{\max }$ at midlatitudes is not entirely clear, but a possible explanation may be that a considerable amount of low clouds at midlatitudes are mixed phase, with melting ice and snow particles contributing considerably to the CPR radar returns.

Regarding cloud base precipitation rates, Sc clouds with open MCC tend to have higher probabilities of moderate to heavy drizzle than Sc clouds with either closed MCC or disorganized MCC. The difference between drizzle rates in closed and open MCCs is more pronounced at midlatitudes than in the subtropics. Given that the average cloud fraction for Sc clouds with open MCC is lower than for low clouds with closed MCC implies that the drizzle rates in open MCCs tend to be stronger but also more localized than in closed MCCs. On the other hand, it is evident that a majority of the Sc clouds with closed MCC produce a significant amount of drizzle, which is agreement with findings from aircraft studies during the VOCALS Regional Experiment (REx) Wood et al. (2011).

\subsection{Cloud top heights}

A fundamental question is whether the differences in the cloud and precipitation characteristics of different Sc cloud morphologies are caused by differences in the number concentrations of aerosols and cloud droplets or by differences in the dynamics and structure of the MBL as indicated by the cloud top height. Figure 10 shows PDFs of cloud top height for the global data, whereas Fig. 13 shows PDFs of cloud top height for the various subtropical and midlatitude regions defined in Table 1. On a global scale, cloud top height is highest for open MCC and lowest for cellular but disorganized MCCs. However, the distribution of the latter is also more heavily skewed than the cloud top height distributions of closed or open MCC categories. The difference in median cloud top height is about $100 \mathrm{~m}$ between the closed and open MCC and about $150 \mathrm{~m}$ between the closed and the cellular but disorganized MCC categories. Based on the nonparametric Wilcoxon rank-sum test (Wilks, 2006), the median cloud top height differences among the MCC categories in the global data set are statistically significant at the $95 \%$ confidence level.

In subtropical regions such as the SEP, the difference in mean cloud top heights between open and closed MCCs is about $10 \mathrm{~m}$ and thus similar to the $15 \mathrm{~m}$ cloud top height difference between overcast Sc cloud regions and POCs observed during VOCALS-REx (Wood et al., 2011). Similarly, the mean cloud top height differences between closed and open MCC in other subtropical regions are approximately $70 \mathrm{~m}$ in the NEP and about $20 \mathrm{~m}$ in the SEA. The small difference in cloud top heights between Sc cloud regions with closed and open-cellular character suggests that the inversion heights capping the MBL are virtually the same in both regions. However, there is indication that the distribution of cloud top heights is broader in the case of open MCCs than 

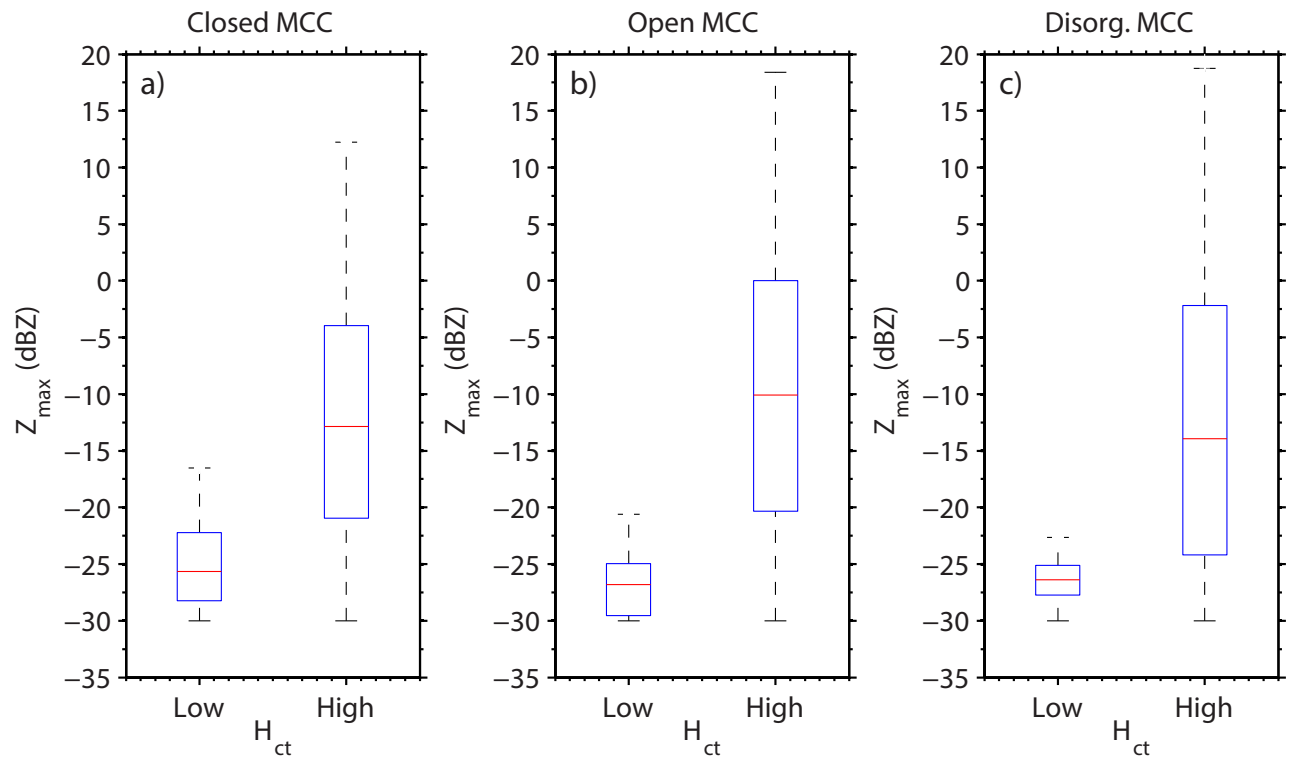

Figure 11. Box-and-whisker plots of column max. radar reflectivity $Z_{\max }$ for each MCC category. The observations are split into two groups with low and high cloud top heights, respectively. The thresholds for dividing the data into two cloud top height groups are based on the 25 th and 75th percentiles of the cloud top height distributions. The median value is shown as a red horizontal line, boxes indicate the interquartile range (25th to 75 th percentile), and the whiskers extend to $\pm 2 \sigma$ of the standard normal distribution.

closed MCCs with higher probability of both high and low cloud tops.

Figure 11 shows box-and-whisker plots of column maximum radar reflectivity of Sc clouds grouped by low and high cloud top heights, respectively. The separation of the observations into the two groups is based on the 25th and 75th percentiles of the underlying cloud top height distribution. For all MCC categories, the majority of low clouds with high cloud top heights have substantially larger column maximum radar reflectivities and thus stronger cloud base drizzle rates than low clouds with low cloud top heights. In other words, thicker Sc clouds rain more.

\section{Radiative properties}

In the following section, we discuss the impact of cloud morphologies on the radiative properties (e.g., cloud optical depth, shortwave reflectance and transmissivity) of marine low-cloud fields. As discussed in Sect. 2, all radiative flux measurements are taken from the integrated CALIPSO CloudSat CERES and MODIS (CCCM) merged data set (Kato et al., 2010, 2011) and interpolated to the A-train ground track to estimate the radiative effect of low clouds as a function of the MCC type. We emphasize that the inferred statistics of radiative properties of MCC types are representative of the cloud field on the scale of several tens of kilometers (including clear-sky pixels) rather than on the scale of individual clouds contributing to the cloud field. This is because the footprint of the CERES instrument is about
$20 \mathrm{~km}$ and thus much larger than the footprint of CloudSat or CALIPSO. Therefore, we are unable to infer the radiative effect of individual Sc clouds but only the radiative effect of the (mesoscale) field of clouds on the scale of a few tens of kilometers.

\subsection{Cloud optical depth}

PDFs of cloud optical depths are shown in Fig. 14. As expected, the distributions of optical depth of low-cloud fields are heavily skewed. Low-cloud fields with closed MCC characteristics tend to have higher values of cloud optical depth than cloud fields with open MCC and disorganized MCC types. This is because fields of clouds with open MCC and cellular but disorganized MCC type have lower cloud fractions and thus larger contributions from clear-sky pixels or optically thin clouds.

\subsection{Reflectance and transmissivity}

The shortwave reflectance (R) is computed as the fraction of shortwave upwelling radiative fluxes at the TOA and the total downwelling radiative flux at the TOA. The shortwave transmissivity $(\mathrm{T})$ is computed as the fraction of downwelling flux at the surface to the total incoming shortwave radiative flux at the TOA.

Previous studies by McFarlane et al. (2013) estimated the radiative impacts of various cloud types on the shortwave transmissivity and longwave cloud radiative effect on the surface for the Atmospheric Radiation Measurement (ARM) tropical western Pacific (TWP) sites and found broad 

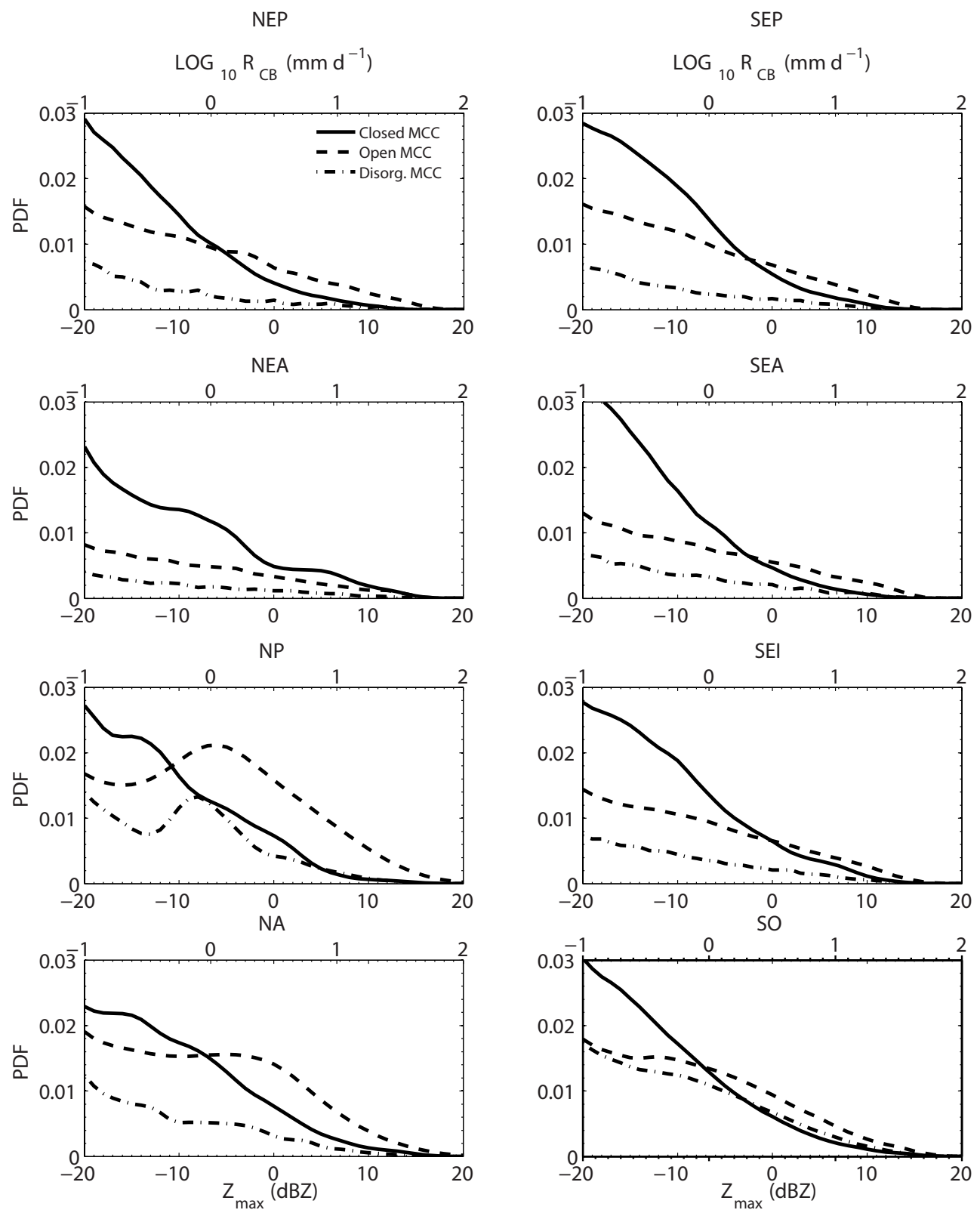

Figure 12. PDFs of column maximum radar reflectivity $\left(Z_{\max }\right)$ for low clouds with closed (solid), open (dashed) and cellular but disorganized (dash-dotted) MCC types for the regions defined in Table 1.

distributions of radiative effects with cloud type and cloud cover being the two major parameters controlling the variability. Similarly, we also find broad distributions for the shortwave reflectance and transmissivity as well as pronounced differences of the radiative effect of Sc cloud fields depending on the cloud morphology and considerable regional variability. PDFs of shortwave reflectance and transmissivity as a function of region and MCC type are shown in Figs. 15 and 16, respectively.

Generally, Sc cloud fields with closed MCC exhibit higher values of shortwave reflectance compared to the other MCC types, which is primarily due to the larger cloud fractions. The mean values for shortwave reflectance for open and cellular but disorganized MCC types are much lower than for closed MCC types but the the PDFs are also more skewed towards higher values. The skewness in the reflectance distribution is caused by the higher variability of cloud fraction for the open and cellular but disorganized MCC categories. The differences in shortwave reflectance demonstrate the importance of low-cloud morphologies and their associated cloudiness on the reflected solar radiation. The mean shortwave reflectance of Sc clouds with closed MCC is about 0.3 for 

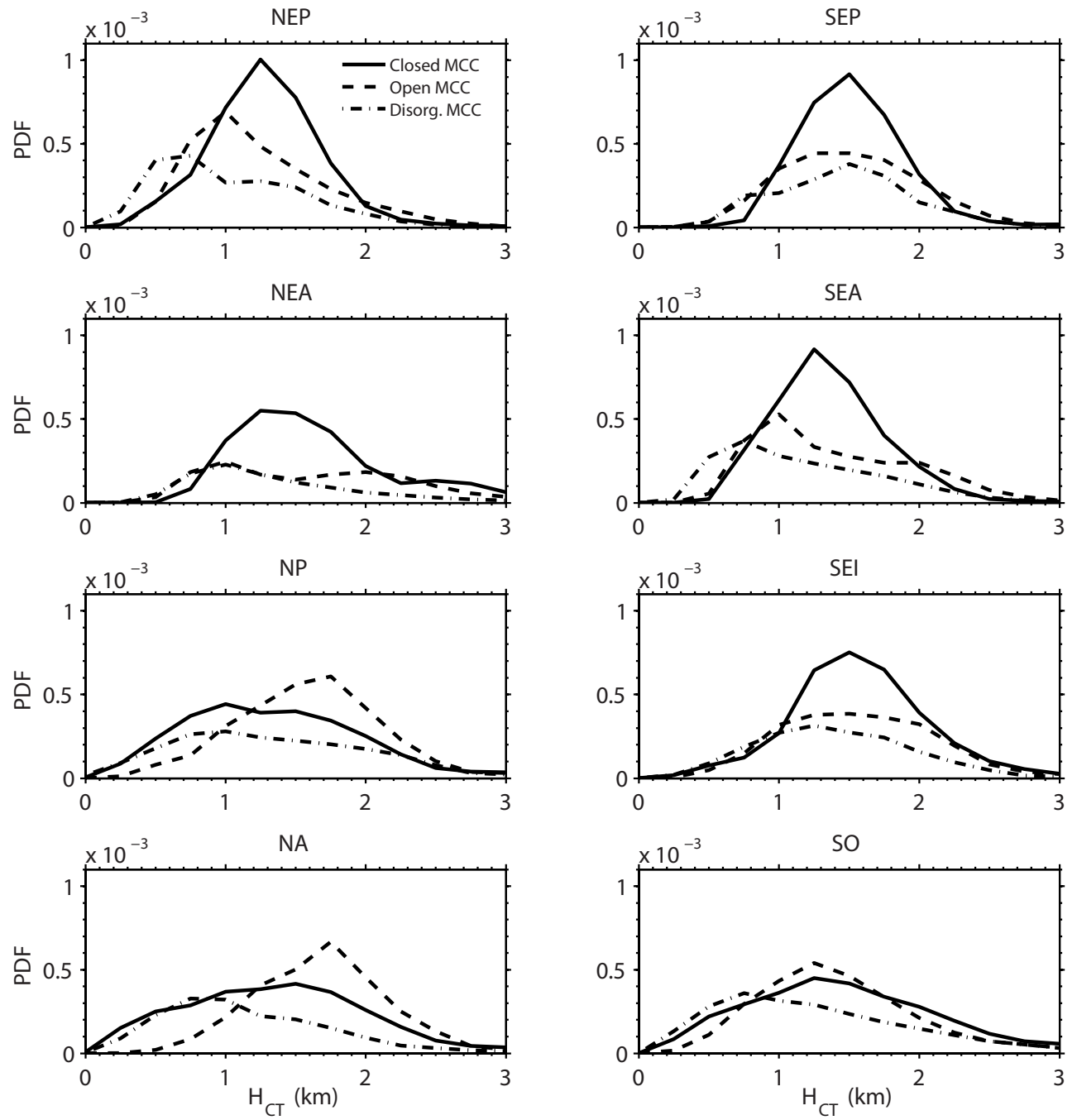

Figure 13. Same as Fig. 12 but for cloud top height $\left(H_{\mathrm{ct}}\right)$.

subtropical regions and on the order of about 0.4 at midlatitudes. The highest values for the shortwave reflectance are found in the SO, and the lowest are found in the NEA. These results highlight the importance of low clouds for the shortwave radiative energy budget and the shortwave cloud forcing at midlatitudes and, in particular, in the SO region.

Similar to the reflectance, the PDFs of shortwave transmissivity show a clear dependence on the type of MCC. Owing to their larger cloud fraction, Sc clouds with closed MCC are considerably less transmissive than Sc clouds with open or cellular but disorganized MCC characteristics. Again, the PDFs of transmissivity are more skewed for open MCC and cellular but disorganized MCC than for closed MCC.

\section{Summary and conclusions}

In this study, we use an artificial neural network cloud classification scheme to identify and discriminate marine low clouds based on their morphology. The cloud morphology involves the type of mesoscale cellular convection (MCC) and the level of organization within the cloud field. The analysis is performed on a global scale and utilizes A-train observations for deriving the frequency of occurrence and seasonal variability of MCC types. A statistical analysis of the physical properties and radiative effects of marine low cloud as a function of their morphology is conducted based on 1 year of A-train data from 2008 and for selected regions at subtropics and midlatitudes. The findings are summarized as follows:

1. In agreement with previous studies based on shipborne cloud observations (Klein and Hartmann, 1993), the largest contributions to cloud fraction from marine low clouds are found in subtropical regions. These regions are characterized by stationary high-pressure systems promoting large-scale subsidence and by upwelling of cold ocean waters resulting in cold sea surface temperatures and strong inversions at the top of the MBL. 

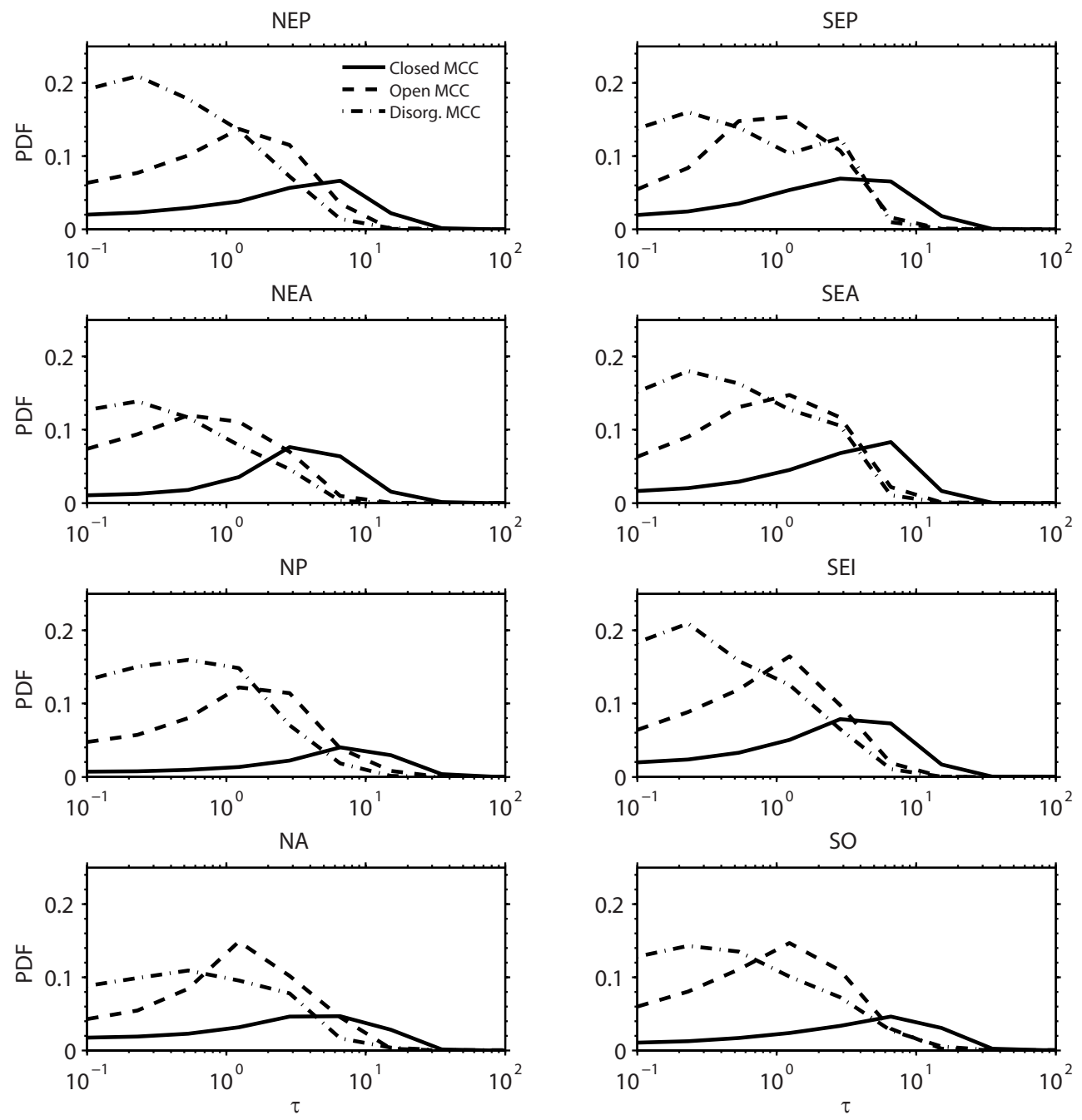

Figure 14. Same as Fig. 12 but for cloud optical depth $(\tau)$.

Considerable contributions to low cloudiness are also found at midlatitude storm tracks of both hemispheres and in the Greenland See (i.e., the Arctic Ocean east of Greenland). In the subtropics, cloud fraction exhibits a pronounced seasonal cycle but the seasonal cycle is damped at midlatitudes and almost absent in the Southern Ocean.

2. On a global scale, the frequency of occurrence of closed MCC types is largest at the subtropics and in the midlatitude storm track regions of both hemispheres, with an increased frequency of occurrence toward higher latitudes. Open MCC types have the lowest frequency of occurrence of all low MCC types with pronounced maximum in the Southeast Pacific, the Southern Ocean and the North Pacific. Within subtropical regions, closed MCC types occur predominantly in near-coastal waters whereas open MCCs are more frequently found further offshore. Cellular but disorganized MCC types are the

dominant MCC type in regions with warm SSTs such as the tropics and the trade wind zones.

3. All MCC types exhibit a pronounced seasonal cycle. In the subtropics, the seasonal cycle of the frequency of occurrence of closed MCC is very well correlated with the seasonal cycle of cloud fraction and the stability within the lower troposphere. Also, there is an anticorrelation in the seasonal cycle of closed MCC and cellular but disorganized MCC, which suggests that as the lower tropospheric stability declines marine low clouds are more likely to transition from closed to disorganized MCCs. At midlatitudes, the seasonality in the occurrence frequency of open MCCs may be linked to cold-air outbreaks and the associated advection of cold continental air masses over warmer ocean surfaces in the wake of cyclones, which happens more often during the winter months. 

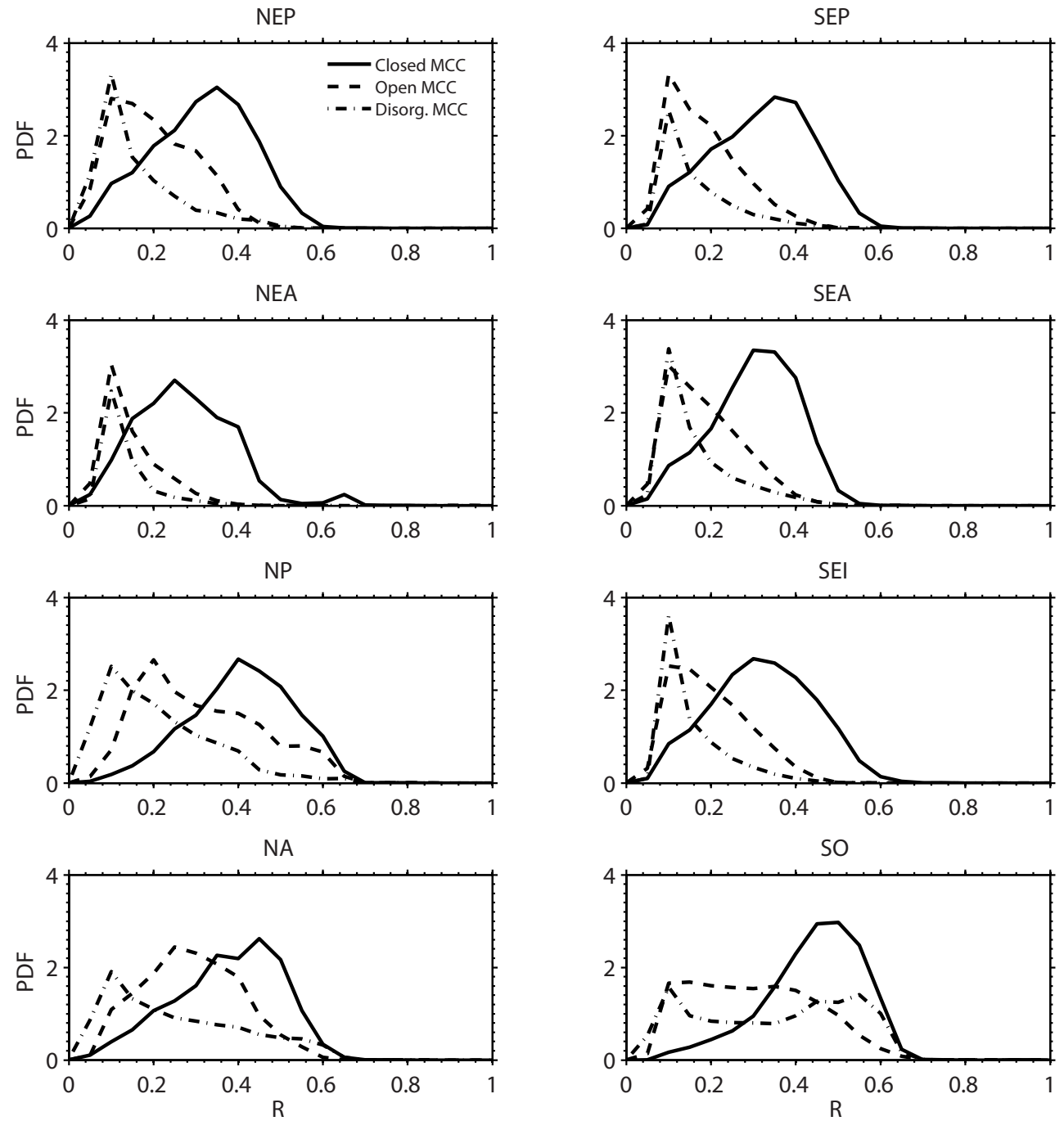

Figure 15. Same as Fig. 12 but for shortwave reflectance (R).

4. The cloud fraction of marine low-cloud fields is highly variable and a function of the MCC type. On a global scale, the cloud fraction is largest for closed MCC, with a mean cloud fraction of about $90 \%$, whereas the cloud fractions are lower for open MCCs and cellular but disorganized MCCs, with mean cloud fractions of about 51 and $40 \%$, respectively. PDFs of cloud fractions are heavily skewed, with modest regional variability in particular for organized open and cellular but disorganized MCC types.

5. PDFs of column maximum CPR reflectivities and cloud base drizzle rates indicate fundamental differences in the cloud and precipitation characteristics of marine low clouds, which are strongly dependent on the MCC type. About $70 \%$ of CPR cloud profiles within closed MCCs have light drizzle, whereas $40 \%$ of the cloud profiles have moderate or heavy drizzle. Within open MCCs,

$40 \%$ of the cloud profiles show light drizzling, whereas $30 \%$ show moderate or heavy drizzling. Within cellular but disorganized MCCs the frequency of occurrence of light and moderate or heavy drizzle is about 30 and $20 \%$, respectively. Given that the mean cloud fraction in marine low-cloud fields with open MCC is substantially lower than for closed MCC implies that drizzle rates in open MCCs are stronger and more localized than in closed MCCs.

6. Mean cloud top heights vary according to MCC type by about $100-200 \mathrm{~m}$. Low clouds with high cloud top heights exhibit substantially larger column maximum radar reflectivities and stronger cloud base drizzle rates than clouds with low cloud top heights. In other words, thicker Sc clouds rain more heavily due to the presence of larger drops. 

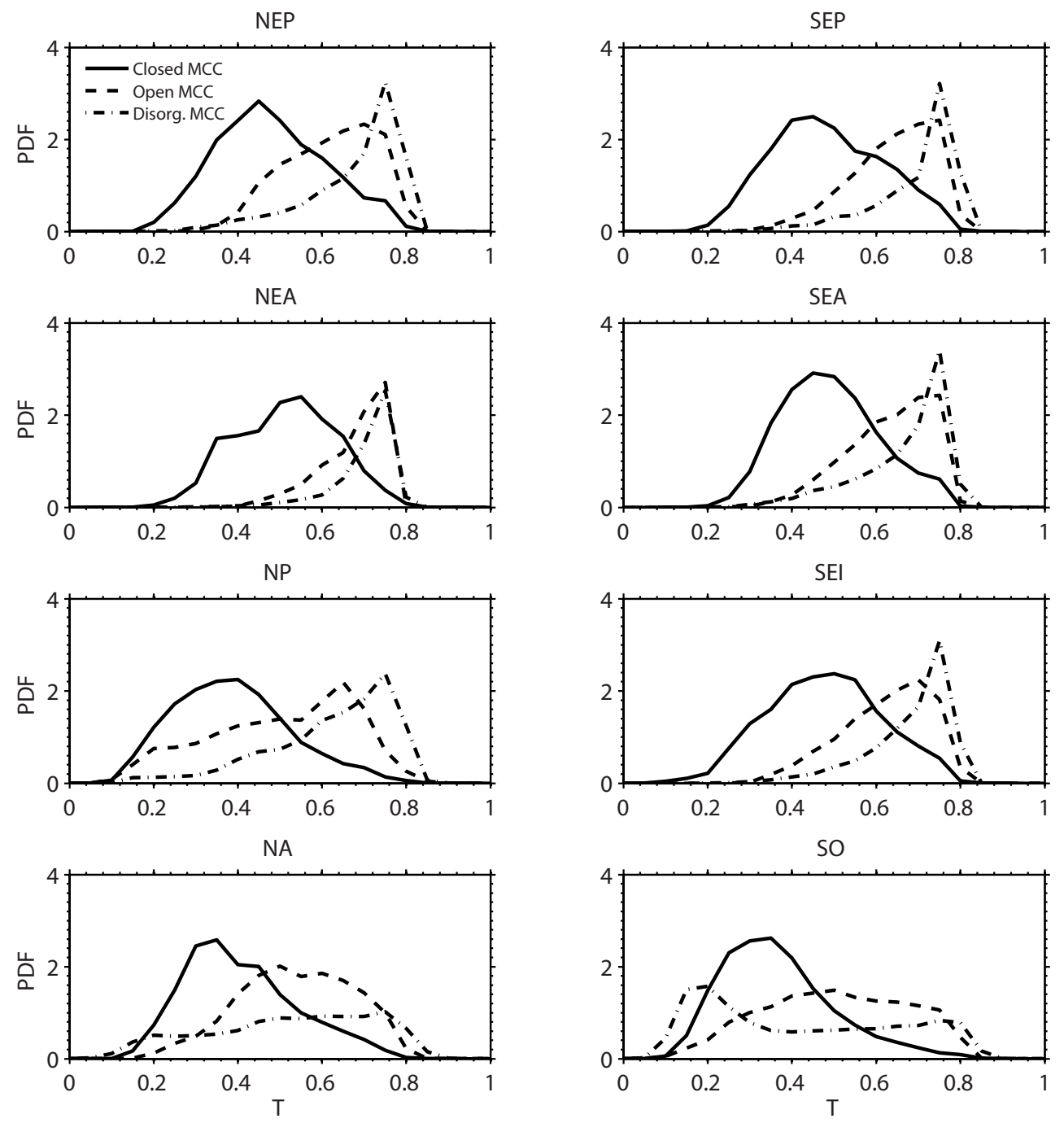

Figure 16. Same as Fig. 12 but for shortwave transmissivity (T).

7. PDFs of cloud optical depths, shortwave reflectance and transmissivity reveal pronounced differences regarding the radiative effect of marine low-cloud fields. The radiative impact of low clouds strongly depends on the cloud morphology and exhibits considerable regional variability. Generally, low clouds with closed MCC exhibit higher values of shortwave reflectance compared to the other MCC types, which is primarily due to the larger cloud fractions. The differences in shortwave reflectance demonstrate the importance of low-cloud morphologies and their associated cloudiness on the reflected solar radiation and thus on the climatic impact of marine low clouds.

Acknowledgements. The authors thank the NASA CloudSat project and the NASA Langley Research Center Atmospheric Science Data Center for providing data, C. Terai for discussions and two anonymous reviewers for numerous helpful comments and suggestions. S. Kato is acknowledged for his support with the CCCM data set. A. Muhlbauer and R. Wood acknowledge funding received from the National Science Foundation (NSF) under grant 1102505. Isabel McCoy acknowledges funding received from the Joint Institute for the Study of the Atmosphere and Ocean (JISAO) during the 2012 JISAO Internship Program. This publication is partially funded by JISAO under NOAA cooperative agreement no. NA10OAR4320148, contribution no. 2204.

Edited by: B. Mayer 


\section{References}

Ackerman, S. A., Strabala, K. I., Menzel, W. P., Frey, R. A., Moeller, C. C., and Gumley, L. E.: Discriminating clear sky from clouds with MODIS, J. Geophys. Res., 103, 32141-32157, doi:10.1029/1998JD200032, 1998.

Agee, E. M.: Meso-scale cellular convection over the oceans, Dyn. Atmos. Oceans, 10, 317-341, 1987.

Atkinson, B. W. and Zhang, J. W.: Mesoscale shallow convection in the atmosphere, Rev. Geophys., 34, 403-431, 1996.

Bolton, D.: The computation of Equivalent Potential Temperature, Mon. Weather Rev., 108, 1046-1053, 1980.

Comstock, K. K., Wood, R., Yuter, S. E., and Bretherton, C. S.: Reflectivity and rain rate in and below drizzling stratocumulus, Q. J. Roy. Meteorol. Soc., 130, 2891-2918, 2004.

Field, P. R. and Wood, R.: Precipitation and cloud structure in midlatitude cyclones, J. Climate, 20, 233-254, 2007.

Hartmann, D. L. and Short, D.: On the use of earth radiation budget statistics for studies of clouds and climate, J. Atmos. Sci., 37, 1233-1250, 1980.

Hartmann, D. L., Ramanathan, V., Berroir, A., and Hunt, G. E.: Earth radiation budget data and climate research, Rev. Geophys., 24, 439-468, 1986.

Im, E., Durden, S. L., and Wu, C.: Cloud Profiling Radar for the CloudSat mission, IEEE Aerosp. Electron. Syst. Mag., 20, 1518, 2006.

Kato, S., Sun-Mack, S., Miller, W. F., Rose, F. G., Chen, Y., Minnis, P., and Wielicki, B. A.: Relationships among cloud occurrence frequency, overlap, and effective thickness derived from CALIPSO and CloudSat merged cloud vertical profiles, J. Geophys. Res., 115, D00H28, doi:10.1029/2009JD012277, 2010.

Kato, S., Rose, F. G., Sun-Mack, S., Miller, W. F., Chen, Y., Ru$\tan$, D. A., Stephens, G. L., Loeb, N. G., Minnis, P., Wielicki, B. A., Winker, D. M., Charlock, T. P., Stackhouse, P. W., Xu, K.M., and Collins, W. D.: Improvements of top-of-atmosphere and surface irradiance computations with CALIPSO-, CloudSat-, and MODIS-derived cloud and aerosol properties, J. Geophys. Res., 116, D19209, doi:10.1029/2011JD016050, 2011.

King, M. D., Kaufman, Y., Menzel, W. P., and Tanre, D.: Remote sensing of cloud, aerosol, and water vapor properties from the moderate resolution imaging spectroradiometer (modis), IEEE Trans. Geosci. Remote Sens., 30, 2-27, 1992.

King, M. D., Menzel, W. P., and Kaufman, Y.: Cloud and aerosol properties, precipitable water, and profiles of temperature and water vapor from modis, IEEE Trans. Geosci. Remote Sens., 41, 442-458, 2003.

Klein, S. A. and Hartmann, D. L.: The Seasonal Cycle of Low Stratiform Clouds, J. Climate, 6, 1587-1606, 1993.

Leon, D. C., Wang, Z., and Li, D.: Climatology of drizzle in marine boundary layer clouds based on 1 year of data from CloudSat and Cloud-Aerosol Lidar and Infrared Pathfinder Satellite Observations (CALIPSO), J. Geophys. Res., 113, D00A14, doi:10.1029/2008JD009835, 2008.

Mace, G. G., Zhang, Q., Vaughan, M., Marchand, R., Stephens, G., Trepte, C., and Winker, D.: A description of hydrometeor layer occurrence statistics derived from the first year of merged Cloudsat and CALIPSO data, J. Geophys. Res., 114, D00A26, doi:10.1029/2007JD009755, 2009.
Marchand, R. T., Mace, G. G., and Ackerman, T. P.: Hydrometeor detection using CloudSat: An Earth orbiting $94 \mathrm{GHz}$ cloud radar, J. Atmos. Oceanic. Technol., 25, 519-533, 2008.

McFarlane, S. A., Long, C. N., and Flaherty, J.: A Climatology of Surface Cloud Radiative Effects at the ARM Tropical Western Pacific Sites, J. Appl. Meteor. Climatol., 52, 996-1013, 2013.

Painemal, D., Garreaud, R., Rutllant, J., and Zuidema, P.: Southeast Pacific Stratocumulus: High-Frequency Variability and Mesoscale Structures over San Fe'lix Island, J. Appl. Meteor. Climatol., 49, 463-477, 2010.

Richter, I. and Mechoso, C. R.: Orographic influences on the annual cycle of Namibian stratocumulus clouds, Geophys. Res. Lett., 31, L24108, doi:10.1029/2004GL020814, 2004.

Rossow, W. B. and Schiffer, R. A.: Isccp cloud data products, B. Am. Meteor. Soc., 72, 2-20, 1991.

Sandu, I., Stevens, B., and Pincus, R.: On the transitions in marine boundary layer cloudiness, Ann. Phys. (NY), 10, 2377-2391, 2010.

Sharon, T. M., Albrecht, B. A., Jonsson, H. H., Minnis, P., Khaiyer, M. M., Reken, T. M. V., Seinfeld, J., and Flagan, R.: Aerosol and Cloud Microphysical Characteristics of Rifts and Gradients in Maritime Stratocumulus Clouds, J. Atmos. Sci., 63, 983-997, 2006.

Stevens, B.: Quasi-steady analysis of a PBL model with an eddydiffusivity profile and nonlocal fluxes, Mon. Weather Rev., 128, 824-836, 2000.

Stevens, B., Vali, G., Comstock, K., Wood, R., VanZanten, M., Austin, P., Bretherton, C., and Lenschow, D.: Pockets of Open Cells (POCs) and drizzle in marine stratocumulus, B. Am. Meteor. Soc., 86, 51-57, 2005.

Stevens, B., Beljaars, A., Bordoni, S., Holloway, C., Kohler, M., Kruger, S., Savic-Jovcic, V., and Zhang, Y. Y.: Understanding macrophysical outcomes of microphysical choices in simulations of shallow cumulus convection, Mon. Weather Rev., 135, 9851005, 2007.

Tanelli, S., Durden, S. L., Im, E., Pak, K. S., Reinke, D. G., Partain, P., Haynes, J. M., and Marchand, R. T.: CloudSat's Cloud Profiling Radar After Two Years in Orbit: Performance, Calibration, and Processing, IEEE T. Geosci. Remote, 46, 3560-3573, 2008.

Terai, C. R., Bretherton, C. S., Wood, R., and Painter, G.: Aircraft observations of five pockets of open cells sampled during VOCALS REx, Atmos. Chem. Phys. Discuss., 14, 8287-8332, doi:10.5194/acpd-14-8287-2014, 2014.

Wilks, D. S.: Statistical Methods in the Atmospheric Sciences, Elsevier Inc., 2nd edn., 2006.

Winker, D. M., Hunt, W. H., and McGill, M. J.: Initial performance assessment of CALIOP, Geophys. Res. Lett., 34, L19803, doi:10.1029/2007GL030135, 2007.

Wood, R.: Stratocumulus Clouds, Mon. Weather Rev., 140, 2373 2423, 2012.

Wood, R. and Bretherton, C. S.: On the relationship between stratiform low cloud cover and lower-tropospheric stability, J. Climate, 19, 6425-6432, 2006.

Wood, R. and Hartmann, D. L.: Spatial variability of liquid water path in marine low cloud: The importance of mesoscale cellular convection, J. Climate, 19, 1748-1764, 2006.

Wood, R., Comstock, K. K., Bretherton, C. S., Cornish, C., Tomlinson, J., Collins, D. R., and Fairall, C.: Open cellular structure 
in marine stratocumulus sheets, J. Geophys. Res., 113, D12207, doi:10.1029/2007JD009371, 2008.

Wood, R., Bretherton, C. S., Leon, D., Clarke, A. D., Zuidema, P., Allen, G., and Coe, H.: An aircraft case study of the spatial transition from closed to open mesoscale cellular convection over the Southeast Pacific, Atmos. Chem. Phys., 11, 2341-2370, doi:10.5194/acp-11-2341-2011, 2011.
Wyant, M. C., Bretherton, C. S., Rand, H. A., and Stevens, D. E.: Numerical simulations and a conceptual model of the stratocumulus to trade cumulus transition, J. Atmos. Sci., 54, 168-192, 1997.

Zhang, Y., Stevens, B., Medeiros, B., and Ghil, M.: Low-Cloud Fraction, Lower-Tropospheric Stability, and Large-Scale Divergence, J. Climate, 22, 4827-4844, 2009. 